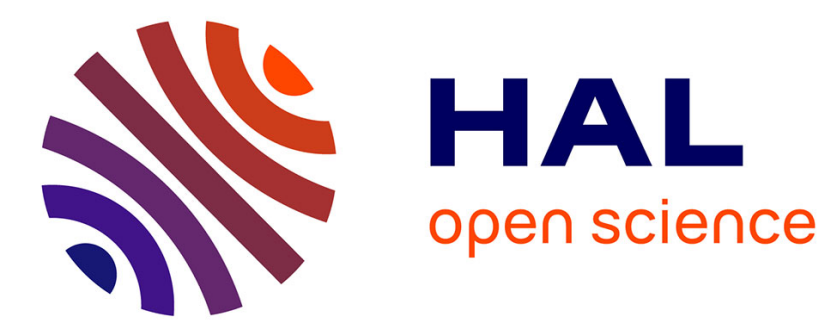

\title{
River network routing on the NHDPlus dataset
}

Cédric H. David, David R. Maidment, Guo-Yue Niu, Zong-Liang Yang, Florence Habets, Victor Eijkhout

\section{To cite this version:}

Cédric H. David, David R. Maidment, Guo-Yue Niu, Zong-Liang Yang, Florence Habets, et al.. River network routing on the NHDPlus dataset. Journal of Hydrometeorology, 2011, 12, pp.913934. 10.1175/2011JHM1345.1. hal-00641713v2

\section{HAL Id: hal-00641713 \\ https://hal.science/hal-00641713v2}

Submitted on 18 Nov 2011

HAL is a multi-disciplinary open access archive for the deposit and dissemination of scientific research documents, whether they are published or not. The documents may come from teaching and research institutions in France or abroad, or from public or private research centers.
L'archive ouverte pluridisciplinaire HAL, est destinée au dépôt et à la diffusion de documents scientifiques de niveau recherche, publiés ou non, émanant des établissements d'enseignement et de recherche français ou étrangers, des laboratoires publics ou privés. 
1 River network routing on the NHDPlus dataset

2 Cédric H. David ${ }^{1,2}$, David R. Maidment ${ }^{2}$, Guo-Yue Niu ${ }^{1,3}$, Zong-Liang Yang ${ }^{1}$, Florence

3 Habets $^{4}$ and Victor Eijkhout ${ }^{5}$

4 1. Department of Geological Sciences, Jackson School of Geosciences, University of

5 Texas at Austin, Austin, Texas, USA.

6 2. Center for Research in Water Resources, University of Texas at Austin, Austin, Texas,

7 USA.

8 3. Biosphere 2, University of Arizona, Tucson, Arizona, USA

9 4. UMR-Sisyphe 7619, CNRS, UPMC, Mines-Paristech, Paris, France.

10 5. Texas Advanced Computing Center, University of Texas at Austin, Austin, Texas,

11 USA.

12 Key words

13 RAPID, streamflow, network, matrix, parallel computing, PETSc, TAO

\section{Corresponding author}

15 Cédric H. David

16 Department of Geological Sciences, Jackson School of Geosciences

17 The University of Texas at Austin

181 University Station C1160

19 Austin, TX 78712

20 cedric.david@mail.utexas.edu 


\section{Abstract}

22 The mapped rivers and streams of the contiguous United States are available in a

23 geographic information system (GIS) dataset called NHDPlus. This hydrographic dataset

24 has about 3 million river and water body reaches along with information on how they are

25 connected into networks. The USGS National Water Information System provides

26 stream flow observations at about 20 thousand gages located on the NHDPlus river

27 network. A river network model called RAPID is developed for the NHDPlus river

28 network whose lateral inflow to the river network is calculated by a land surface model.

29 A matrix-based version of the Muskingum method is developed herein which RAPID

30 uses to calculate flow and volume of water in all reaches of a river network with many

31 thousands of reaches, including at ungaged locations. Gages situated across river basins

32 (not only at basin outlets) are used to automatically optimize the Muskingum parameters

33 and to assess river flow computations; hence allowing the diagnosis of runoff

34 computations provided by land surface models. RAPID is applied to the Guadalupe and

35 San Antonio River Basins in Texas, where flow wave celerities are estimated at multiple

36 locations using 15-minute data and can be reproduced reasonably with RAPID. This

37 river model can be adapted for parallel computing and although the matrix method

38 initially adds a large overhead, river flow results can be obtained faster than with the

39 traditional Muskingum method when using a few processing cores, as demonstrated in a 40 synthetic study using the Upper Mississippi River Basin. 


\section{1. Introduction}

43 Land surface models (LSMs) have been developed by the atmospheric science

44 community to provide atmospheric models with bottom boundary conditions (water and

45 energy balance) and to serve as the land base for hydrologic modeling. Over the past two

46 decades, overland and subsurface runoff calculations done by LSMs have extensively

47 been used to provide water inflow to river routing models that calculate river discharge

48 [De Roo, et al., 2003; Habets, et al., 1999a; 1999b; 1999c; 2008; Lohmann, et al., 1998a;

49 1998b; 2004; Maurer, et al., 2001; Oki, et al., 2001; Olivera, et al., 2000]. However,

50 river routing within LSMs has traditionally been done using gridded river networks that

51 best fit the computational domain used in LSMs. Today, geographic information system

52 (GIS) hydrographic datasets are increasingly becoming available at the continental scale

53 such as NHDPlus [USEPA and USGS, 2007] and the global scale such as HydroSHEDS

54 [Lehner, et al., 2006]. These datasets provide a vector-based representation of the river

55 network using the "blue line" mapped rivers and streams. Furthermore, observations of

56 the river systems are now widely available in databases such as the USGS National Water

57 Information System for the United States in which thousands of gages are available along

58 with their exact location on the NHDPlus river network. Most studies mentioned above -

59 with the exception of Habets et al. [2008] - use a limited number of gages throughout

60 large river basins, often focusing on gages located at river mouths. As the spatial and

61 temporal resolutions of weather and climate models and their underlying land surface

62 models increase, using gages located across basins would help diagnosing the quality of

63 LSM computations. The latest work on general circulation models by the international

64 scientific community, especially by the intergovernmental panel on climate change 
65 [Solomon, et al., 2007], opens potential studies of the evolution of water resources with

66 global change. Using mapped streams and water bodies in LSMs could benefit the

67 resulting assessment of the impact of global change in water resources by providing

68 estimation of changes at the "blue line" level. Furthermore, the use of parallel computing

69 is quite common in regional- to global-scale atmospheric and ocean modeling, but

70 comparatively infrequent in modeling of large river networks. Generally, parallel

71 computing can be utilized to either solve problems of increasing size [as done with the

72 ParFlow model: Jones and Woodward, 2001; Kollet and Maxwell, 2006; Kollet, et al.,

73 2010] or to decrease computation time [see, for example: Apostolopoulos and

74 Georgakakos, 1997; Larson, et al., 2007; Leopold, et al., 2006; von Bloh, et al., 2010].

75 These two types of approaches to parallel computing are respectively referred to as

76 scalability and speedup of calculations and the work presented herein focuses on the

77 latter. Apostolopoulos and Georgakakos [1997] investigated the speedup of streamflow

78 computations using hydrologic models in river networks as a function of network

79 decomposition and of the computing time ratio between vertical and horizontal water

80 balance calculations. Simple river routing within LSMs being traditionally performed by

81 carrying computations from upstream to downstream, one way to speedup river flow

82 modeling is to use a sequential river routing code to compute independent basins on

83 different processing cores, as done in Leopold et al. [2006] and in Larson et al. [2007].

84 Such methods allow avoiding inter-processor communication but result in imbalanced

85 computing loads when some basins are much larger than others. Leopold et al. [2006]

86 partly addressed load imbalance by using parallel computing for surface water balance,

87 but the river routing part remains sequential. von Blow et al. [2010] implemented a 
88 routing method in which computations do not have to be carried in order from upstream

89 to downstream, therefore obtaining almost perfect speedup. The work developed herein

90 investigates a way to obtain speedup while retaining traditional upstream-to-downstream

91 computations which are used in most river routing schemes.

92 The present study links a land surface model with a new river network model called

93 RAPID using NHDPlus for the representation of the river network and USGS National

94 Water Information System (NWIS) gages for the optimization of model parameters and

95 the assessment of river flow computations. All models and datasets used herein are

96 available at least for the contiguous United States. The work presented here focuses first

97 on the Guadalupe and San Antonio Basins in Texas (see Figure 1) together covering a

98 surface area of about $26,000 \mathrm{~km}^{2}$. These basins have about 5,000 river reaches and their

99 corresponding catchments in the NHDPlus dataset (see Figure 2) out of 3 million for the

100 United States. These two basins are also chosen for study because of significant

101 contributions to surface water flow from groundwater sources, because of a large

102 reservoir, at Canyon Lake, where the impacts of constructed infrastructure on flow

103 dynamics have to be considered, and because these rivers flow out into an estuarine

104 system at San Antonio Bay. A synthetic study of the performance of RAPID in a parallel

105 computing environment is also presented using the Upper Mississippi River Basin (see

106 Figure 3), which has about 180,000 river reaches in NHDPlus and covers an area of about $107490,000 \mathrm{~km}^{2}$.

108 The research presented in this paper aims at answering the following questions: how can

109 a river model be developed for calculation of flow and volume of water in a river network

110 of thousands of "blue-line" river reaches? How can the connectivity information in 
111 NHDPlus be used to run a river network model in part of the United States? How can

112 flow at ungaged locations be reconstructed? How can model computations be assessed

113 and optimized based on all available measurements? How can parallel computing be

114 used to speedup upstream-to-downstream computations of river flow within a large river

115 network?

116 First, the development of the RAPID model presented. Then, the modeling framework

117 for calculation of river flow in the Guadalupe and San Antonio River Basins using runoff

118 data from a land surface model is developed, followed by results. Finally, the speedup of

119 RAPID in a parallel computing environment is assessed.

120 


\section{2. Model development}

122 The model presented here is named RAPID (Routing Application for Parallel

123 computatIon of Discharge - http://www.geo.utexas.edu/scientist/david/rapid.htm).

124 RAPID is based on the traditional Muskingum method that was first introduced by

125 McCarthy [1938] and has been extensively studied in the literature in the past 70 years.

126 The Muskingum method has two parameters, $k$ and $x$, respectively a time and a

127 dimensionless parameter. Among the most noteworthy papers related to the Muskingum

128 method, Cunge [1969] showed the Muskingum method is a first-order approximation of

129 the kinematic and diffusive wave equation and proposed a method known as the

130 Muskingum-Cunge method - a second-order approximation of the kinematic and

131 diffusive wave equation - in which the Muskingum parameters are computed based on

132 mean physical characteristics of the river channel and of the flow wave. Koussis [1978]

133 proposed a variable-parameter Muskingum method based on the Muskingum-Cunge

134 method where $k$ varies with the flow but $x$ remains constant on the grounds that the

135 Muskingum method is relatively insensitive to this parameter. Other variable-parameter

136 Muskingum methods allow both $k$ and $x$ to vary [see, for example: Miller and Cunge,

137 1975; Ponce and Yevjevich, 1978], although these variable-parameter methods fail to

138 conserve mass [Ponce and Yevjevich, 1978]. Notable large-scale uses of the variable-

139 parameter Muskingum-Cunge method include Orlandini and Rosso [1998] and Orlandini

140 et al. [2003]. More recently, Todini [2007] developed a mass-conservative variable-

141 parameter Muskingum method known as the Muskingum-Cunge-Todini method.

142 As a first step, the traditional Muskingum method with temporally-constant parameters

143 calculated partly based on the work of Cunge [1969] is used in this study because there 
144 are significant challenges to overcome in adapting the Muskingum method for river

145 networks, in efficiently running it within a parallel computing environment and in

146 developing an automated parameter estimation procedure before more sophisticated flow

147 equations are used. However, the physics of flow could be improved with many

148 variations based on the Muskingum method or adapted to the Saint Venant equations.

$149 \quad$ 2.1 Calculation of flow and volume of water in a river network

150 In a network of thousands of reaches, matrices are needed for network connectivity and

151 flow computation. The backbone of RAPID is a vector-matrix version of the Muskingum

152 method shown in Equation (1) and derived subsequently in this section.

$$
\left(\mathbf{I}-\mathbf{C}_{\mathbf{1}} \cdot \mathbf{N}\right) \cdot \mathbf{Q}(t+\Delta t)=\mathbf{C}_{\mathbf{1}} \cdot \mathbf{Q}^{\mathrm{e}}(t)+\mathbf{C}_{\mathbf{2}} \cdot\left[\mathbf{N} \cdot \mathbf{Q}(t)+\mathbf{Q}^{\mathrm{e}}(t)\right]+\mathbf{C}_{\mathbf{3}} \cdot \mathbf{Q}(t)
$$

156 where $t$ is time and $\Delta t$ is the river routing time step. The bolded notation is used for

157 vectors and matrices. $\mathbf{I}$ is the identity matrix. $\mathbf{N}$ is the river network matrix. $\mathbf{C}_{\mathbf{1}}, \mathbf{C}_{\mathbf{2}}$ and $158 \mathbf{C}_{\mathbf{3}}$ are parameter matrices. $\mathbf{Q}$ is a vector of outflows from each reach, and $\mathbf{Q}^{\mathbf{e}}$ is a vector 159 of lateral inflows for each reach. Such a vector-matrix formulation of the Muskingum 160 method has to our knowledge never been previously published.

161 Equation (1) is used for river network routing and can be solved using a linear system 162 solver. The vector-matrix notation provides one flow equation for the entire river 163 network, therefore avoiding spatial iterations. For a river network with $m$ river reaches, 164 all vectors are of size $m$ and all matrices are square of size $m$. Each element of a vector 165 corresponds to one river reach in the network. For performance purposes, all matrices are 
166 stored as sparse matrices (only the non-zero values are recorded). A five-reach, two-node

167 and two-gage river network is used here to clarify the mathematical formulation of the

168 river network model and is shown in Figure 4a). The river network is made up of a

169 combination of river reaches similar to that of Figure $4 b$ ). The model formulation is

170 presented here for a small river network but can be generalized to any size of river

171 network.

$172 \mathbf{Q}$ is a vector of the outflows $Q_{j}$ of all reaches of the river network, where $j$ is the index

173 of a river reach within the network:

174

175

$$
\mathbf{Q}(t)=\left[\begin{array}{l}
Q_{1}(t) \\
Q_{2}(t) \\
Q_{3}(t) \\
Q_{4}(t) \\
Q_{5}(t)
\end{array}\right]=\left[Q_{j}(t)\right]_{j \in[1, m]}
$$

$177 \mathbf{Q}^{\mathrm{e}}$ is a vector of flows $Q_{j}^{e}$ that are lateral inflows to the river network. Lateral inflows

178 include runoff, groundwater or any type of forced inflow (outflow at a dam, pumping,

179 etc.):

180

$$
\mathbf{Q}^{\mathbf{e}}(t)=\left[Q_{j}^{e}(t)\right]_{j \in[1, m]}
$$

$183 \mathbf{Q}^{\mathbf{e}}$ is provided by a land surface model, whose time step is coarser than the river routing

184 time step. Two assumptions are made in the development of RAPID, one regarding the 
185 temporal variability of $\mathbf{Q}^{\mathbf{e}}$ and one regarding the location at which $\mathbf{Q}^{\mathbf{e}}$ enters the river

186 network. In this study, the river routing time step is 15 minutes and inflow from land

187 surface runoff is available every 3 hours. In the derivation of Equation (1), $\mathbf{Q}^{\mathbf{e}}$ is

188 assumed constant (i.e. $\left.\mathbf{Q}^{\mathbf{e}}(t+\Delta t)=\mathbf{Q}^{\mathbf{e}}(t)\right)$ over all 15-minute river routing time steps

189 included within a given land surface model 3-hour time step. This partial temporal

190 uniformity simplifies the river network model formulation, limits the quantity of input

191 data and facilitates the coupling with land surface models. This assumption is valid at all

192 times except at the last routing time steps before a new $\mathbf{Q}^{\mathbf{e}}$ is made available by the land

193 surface model. Also, the external inflow $\mathbf{Q}^{\mathbf{e}}$ is assumed to enter the network as an

194 addition to the upstream flow. With these two assumptions, the Muskingum method

195 applied to reach 5 in Figure 4b) gives the following:

196

$$
\begin{aligned}
Q_{5}(t+\Delta t) & =C_{1} \cdot\left[Q_{3}(t+\Delta t)+Q_{4}(t+\Delta t)+Q^{e}{ }_{5}(t)\right] \\
& +C_{2} \cdot\left[Q_{3}(t)+Q_{4}(t)+Q^{e}{ }_{5}(t)\right] \\
& +C_{3} \cdot Q_{5}(t)
\end{aligned}
$$

199 where $C_{1}, C_{2}$ and $C_{3}$ are the Muskingum parameters that are stated in Equation (6). The

200 reader should note that these two assumptions are equivalent to using a unit-width lateral

201 inflow along with a term $C_{4}$ as found in available literature [see, for example: Fread,

202 1993; NERC, 1975; Orlandini and Rosso, 1998; Ponce, 1986]. Equation (1) is a

203 generalization of Equation (4) using a vector-matrix notation. 
$204 \mathbf{N}$ is a network connectivity matrix. Berge [1958] proposed the concept of matrices

205 associated with graphs. This concept can be applied to the river network in Figure 4a) in

206 order to create the network matrix $\mathbf{N}$ given in Equation (5) in both full and sparse

207 formats. The network connectivity matrix is a square matrix whose dimension is the total

208 number of reaches in the network. A value of one is used at row $i$ and column $j$ if reach

$209 j$ flows into reach $i$ and zero is used everywhere else.

210

$$
\mathbf{N}=\left[\begin{array}{lllll}
0 & 0 & 0 & 0 & 0 \\
0 & 0 & 0 & 0 & 0 \\
1 & 1 & 0 & 0 & 0 \\
0 & 0 & 0 & 0 & 0 \\
0 & 0 & 1 & 1 & 0
\end{array}\right]=\left[\begin{array}{llll} 
& & & \\
& & & \\
1 & 1 & & \\
& & & \\
& 1 & 1
\end{array}\right]
$$

213 The upstream inflow to the network can therefore be computed by multiplying the

214 network connectivity matrix $\mathbf{N}$ by the vector of outflows $\mathbf{Q}$. In case of a divergence in

215 the river network (when going downstream) or in case of a loop, a unique reach (the

216 major divergence) is used to carry all the upstream flow and the other reaches (minor

217 divergences) carry only the flow that results from their lateral inflow. This formulation

218 could be modified to take into account given fractions of flows that separate into different

219 parts of a divergence if that information is available.

$220 \mathbf{C}_{1}, \mathbf{C}_{2}$ and $\mathbf{C}_{3}$ are diagonal matrices with their diagonal elements being the coefficients

221 used in the Muskingum method [McCarthy, 1938], respectively $C_{1 j}, C_{2 j}$ and $C_{3 j}$ such

222 that: 


$$
C_{1 j}=\frac{\frac{\Delta t}{2}-k_{j} \cdot x_{j}}{k_{j} \cdot\left(1-x_{j}\right)+\frac{\Delta t}{2}}, \quad C_{2 j}=\frac{\frac{\Delta t}{2}+k_{j} \cdot x_{j}}{k_{j} \cdot\left(1-x_{j}\right)+\frac{\Delta t}{2}}, \quad C_{3 j}=\frac{k_{j} \cdot\left(1-x_{j}\right)-\frac{\Delta t}{2}}{k_{j} \cdot\left(1-x_{j}\right)+\frac{\Delta t}{2}}
$$

226 where $k_{j}$ is a storage constant (with dimension of a time) and $x_{j}$ a dimensionless

227 weighting factor characterizing the relative influence of the inflow and the outflow on the 228 volume of the reach $j$. The Muskingum method is stable for any $x \in[0,0.5]$, regardless

229 of the value of $k$ and $\Delta t$ [Cunge, 1969]. For any $j: C_{1 j}+C_{2 j}+C_{3 j}=1$.

230 In RAPID, the parameters $k$ and $x$ of the Muskingum method are allowed to differ from

231 one river reach to another, and corresponding vectors are defined in Equation (7):

$$
\mathbf{k}=\left[k_{j}\right]_{j \in[1, m]} \quad, \quad \mathbf{x}=\left[x_{j}\right]_{j \in[1, m]}
$$

235 The constants defined in Equation (6) are used as the diagonal elements of the matrices

$236 \mathbf{C}_{\mathbf{1}}, \mathbf{C}_{\mathbf{2}}$ and $\mathbf{C}_{\mathbf{3}}$. Equation (8) shows an example for $\mathbf{C}_{\mathbf{1}} . \mathbf{C}_{\mathbf{2}}$ and $\mathbf{C}_{\mathbf{3}}$ are treated similarly.

$$
\mathbf{C}_{1}=\left[\begin{array}{lllll}
C_{1_{1}} & & & & \\
& C_{1_{2}} & & & \\
& & C_{1_{3}} & & \\
& & & C_{1_{4}} & \\
& & & & C_{1_{5}}
\end{array}\right]
$$


240 The sum $\mathbf{C}_{\mathbf{1}}+\mathbf{C}_{\mathbf{2}}+\mathbf{C}_{\mathbf{3}}$ equals the identity matrix.

241 The calculation of the volume of water in a given reach can be needed for coupling with

242 groundwater models. Here, the first order, explicit, forward Euler method is applied to

243 the continuity equation to calculate the volume of water in each river reach of the

244 network, as shown in Equation (9) where the first, second and third terms of the right-

245 hand-side are the volume of water that respectively were in the river reach, flowed into

246 the reach, and discharged from the reach:

$$
\mathbf{V}(t+\Delta t)=\mathbf{V}(t)+\left[\mathbf{N} \cdot \mathbf{Q}(t)+\mathbf{Q}^{\mathrm{e}}(t)\right] \cdot \Delta t-\mathbf{Q}(t) \cdot \Delta t
$$

250 where $\mathbf{V}$ is a vector of the volume of water $V_{j}$ in each river reach $j$ :

$$
\mathbf{V}(t)=\left[V_{j}(t)\right]_{j \in[1, m]}
$$

254 Details on the massively-parallel implementation of the matrix-based Muskingum

255 method presented in this section, and of the automated parameter estimation presented in

256 the section below are given in Appendix A.

\section{$257 \quad 2.2$ Parameter estimation}

258 In order to estimate the parameters $\mathbf{k}$ and $\mathbf{x}$ to be used in RAPID, an inverse method is

259 developed. The principle of an inverse method is to optimize the parameters of a model

260 so that the outputs of the model approach observations. A cost function reflecting the 
261 difference between model calculations and observations is needed to assess the quality of 262 a set of model parameters. The best set of parameters is chosen as the set that minimizes

263 the cost function, and is determined through optimization. A square-error cost function $264 \phi$ is chosen:

$$
\phi(\mathbf{k}, \mathbf{x})=\sum_{t=t_{o}}^{t=t_{f}}\left[\left(\frac{\overline{\mathbf{Q}}(t)-\mathbf{Q}^{\mathbf{g}}(t)}{f}\right)^{T} \cdot \mathbf{G} \cdot\left(\frac{\overline{\mathbf{Q}}(t)-\mathbf{Q}^{\mathbf{g}}(t)}{f}\right)\right]
$$

268 where the summation is made daily. The $T$ in exponent is for vector transpose. $t_{o}$ and

$269 t_{f}$ are respectively the first day and last day used for the calculation of $\phi$. The model

270 parameter vectors $\mathbf{k}$ and $\mathbf{x}$ are kept constant within the temporal interval $\left[t_{o}, t_{f}\right]$, and the

271 cost function is calculated several times with different sets of parameters during the

272 optimization procedure. $f$ is a scalar that allows $\phi$ to be on the order of magnitude of

$27310^{1}$ which is helpful for automated optimization procedures. $\overline{\mathbf{Q}}(t)$ is the daily-average

274 outflow vector, calculated based on the mean of all routing time steps in a given day.

$275 \mathbf{Q}^{\mathrm{g}}(t)$ is a vector with the total number of river reaches for dimension, with the daily

276 value observed $Q_{j}^{g}(t)$ corresponding to reach $j$ where gage measurements are available,

277 and zero where no gage is available. $\mathbf{G}$ is a sparse diagonal matrix that allows the dot-

278 product to survive only where gages are available, so that $\mathbf{G}$ has a value of one on the 
279 diagonal element of index $j$ if a gage is available on reach $j$ and zero everywhere else.

280 Using the example network given in Figure 4a), $\mathbf{G}$ and $\mathbf{Q}^{\mathrm{g}}(t)$ take the following form:

$$
\mathbf{G}=\left[\begin{array}{lll}
1 & \\
& & \\
& & 1
\end{array}\right], \quad \mathbf{Q}^{\mathrm{g}}(t)=\left[\begin{array}{c}
0 \\
0 \\
\mathbf{Q}_{3}^{\mathrm{g}}(t) \\
0 \\
\mathbf{Q}_{5}^{\mathrm{g}}(t)
\end{array}\right]
$$

284 According to Fread [1993], $x \in[0.1 ; 0.3]$ in most streams. By analogy with the kinematic 285 wave equation, Cunge [1969] showed that the parameter $k$ of the Muskingum method is 286 the travel time of a flow wave through a river reach. For a given river reach $j$ of length

$287 L_{j}$ where a flow wave of celerity $c_{j}$ travels, $k_{j}$ is obtained by dividing the length by the 288 celerity of the wave, as shown in Equation (13):

$$
k_{j}=\frac{L_{j}}{c_{j}}
$$

292 Although the routing model defined by Equation (1) allows for variability of the

293 parameters $\left(k_{j}, x_{j}\right)$ on a reach-to-reach basis, attempting to automatically estimate model

294 parameters independently for all the reaches of a basin would be a costly undertaking.

295 Therefore, the search for optimal parameters is limited to determining two multiplying

296 factors $\lambda_{k}$ and $\lambda_{x}$ such that: 


$$
k_{j}=\lambda_{k} \cdot \frac{L_{j}}{c_{j}} \quad, \quad x_{j}=\lambda_{x} \cdot 0.1
$$

300 To minimize the influence of the initial guess on the optimization procedure, three

301 different initial guesses for $\left(\lambda_{k}, \lambda_{x}\right)$ are used. Out of the three corresponding optimal

$302\left(\lambda_{k}, \lambda_{x}\right)$ obtained, only the one couple leading to the minimum value of the cost function

$303 \phi$ is kept. Therefore, the optimization procedure leads to only one optimal couple

$304\left(\lambda_{k}, \lambda_{x}\right)$ for a given basin in the network. Note that - as a first step $-\mathbf{x}$ is here constant

305 over a given basin on the grounds that the Muskingum method is relatively insensitive to

306 this parameter [Koussis, 1978]. Some data available in NHDPlus (such as mean flow,

307 mean velocity, slope, etc.) associated with available formulations for $\mathbf{x}$ [for example:

308 Cunge, 1969; Orlandini and Rosso, 1998] could be used to improve the proposed

309 method. 
311 RAPID is designed to handle large routing problems. Given a river network and

312 connectivity information as well as lateral inflow to the river network, RAPID can run on

313 any river network. In this study, a framework for computation of river flow in the

314 Guadalupe and San Antonio River Basins is developed that uses a one-way modeling

315 framework with an atmospheric dataset, a land surface model and RAPID as the river

316 model. This section presents how the Guadalupe and San Antonio River Basins are

317 described in the NHDPlus dataset, how a land surface model is used to provide lateral

318 inflow to the river network, and how the meteorological forcing is prepared.

\section{3.1. RAPID used on NHDPlus}

320 There are a total of 5175 river reaches with known direction and connectivity within the

321 NHDPlus description of the Guadalupe and San Antonio river basins (as shown in Figure

322 2). These 5175 reaches have an average length of $3.00 \mathrm{~km}$ and the average catchment

323 defined around them is $5.11 \mathrm{~km}^{2}$ in area; all are used for this study. Details on the fields

324 used in the NHDPlus dataset including the unique identifier COMID used for all river

325 reaches and their corresponding catchments; and on how NHDPlus is used with RAPID

326 are given in Appendix B. In this study, the vector of outflows in all river reaches $\mathbf{Q}$ was

327 arbitrarily initialized to the uniform value of $0 \mathrm{~m}^{3} \mathrm{~s}^{-1}$ prior to running RAPID.

\section{3.2. Land surface model and coupling with RAPID}

329 Within this study, the core physical model governing the one-dimensional vertical fluxes

330 of energy and moisture is the Community Noah Land Surface Model with Multi-Physics

331 Options, hereafter referred to as Noah-MP [Niu, et al., 2010]. Noah-MP offers multiple

332 options for choosing the modeling of certain physical phenomena. In this study, the soil 
333 moisture factor for stomatal resistance is of "Noah type" [Niu, et al., 2010] and the runoff

334 scheme is from "SIMGM" [Niu, et al., 2007]. The soil column is 2 meter deep, below

335 which is an unconfined aquifer. In order to represent the characteristics of the structural

336 soil over the model domain, the saturated hydraulic conductivity, which is determined by

337 the soil texture data, is enlarged by factor of ten (through calibration). The soil

338 hydrology of Noah (soil moisture) is run at an hourly time step and runoff data are

339 produced every three hours. In this study, the state variables of Noah were initialized

340 through a spin-up method.

341 Noah-MP calculates the amount of water that runs off on and below the land surface.

342 This quantity is used to provide RAPID with the water inflow from outside of the river

343 network. David et al. [2009] presented a coupling technique using a hydrologically

344 enhanced version of the Noah LSM called Noah-distributed [Gochis and Chen, 2003]

345 that allows physically-based modeling of the horizontal movement of surface and

346 subsurface water from the land surface to a river reach. In interest of a simpler coupling

347 scheme, the work of David et al. [2009] has been modified. In this study, a flux coupler

348 between Noah and RAPID is developed using the catchments available in the NHDPlus

349 dataset.

350 The NHDPlus catchments contributing runoff to each river reach were determined as part

351 of the NHDPlus development using a digital elevation model and its associated flow

352 accumulation and flow direction grids. These grids have a native resolution of $30 \mathrm{~m}$.

353 The map of catchments is available in NHDPlus in both gridded (at 30-m resolution) and

354 vector formats in a shapefile. Running a land surface model at a 30-m resolution is very

355 resource demanding. Therefore, a coarser resolution of $900 \mathrm{~m}$ cell size is chosen. The 
356 shapefile of NHDPlus catchment boundaries is converted to a grid of size $900 \mathrm{~m}$. Within

357 this conversion process, the accuracy of the boundaries of the catchments is lowered but

358 the catchment boundaries are reasonably respected and the computational cost of the land

359 surface model calculations is reasonable. For each 3-hour output of the Noah model,

360 surface and subsurface runoff data is superimposed onto the catchment grid, and all

361 runoff that corresponds to the catchment of each river reach is summed and used as the

362 water inflow to the river reach. Figure 5 shows the principle of the flux coupler in which

363 the 900-m runoff data generated by the Noah model is superposed to the 900-m map of

364 NHDPlus catchment COMIDs to determine the lateral inflow for NHDPlus reaches used

365 by RAPID.

366 Therefore, no horizontal routing is used between the land surface and the river network in

367 the proposed scheme. This differs from some other models that use runoff from a one-

368 dimensional model to force a river routing model. For instance, the two dimensional

369 wave equation is used in Gochis and Chen [2003] or the linear reservoir equation is used

370 in Ledoux et al. [1989].

371 The coupling method used here can be adapted to any land surface model that computes

372 surface and subsurface runoff on a grid. This coupling technique is automated in a

373 Fortran program.

\section{3.3. Meteorological forcing}

375 Land surface models need meteorological forcing in order to compute the water and the

376 energy balance at the surface. The Noah LSM requires seven meteorological parameters:

377 precipitation, specific humidity, air temperature, air pressure, wind speed, downward

378 shortwave and downward longwave radiation. Hourly precipitation is obtained from 
379 NEXRAD and downscaled from its original resolution $(4.763 \mathrm{~km})$ to $900 \mathrm{~m}$ using the 380 method developed in Guan et al. [2009]. All other meteorological parameters are

381 downloaded from the 3-hourly North American Regional Reanalysis (NARR) and

382 converted from its original resolution $(32.463 \mathrm{~km})$ to $900 \mathrm{~m}$ using a simple triangle-base

383 linear interpolation. All meteorological data are prepared for four years (01 January 2004

$384-31$ December 2007).

385

386 


\section{Calibration and results for the Guadalupe and San Antonio River Basins}

388 The framework for computation of river flow that is developed in the previous section is

389 used to calculate river flow in all 5175 river reaches of the Guadalupe and San Antonio

390 River Basins for four years (01 January 2004 - 31 December 2007). In this section, flow

391 wave celerities in several sub-basins are estimated from measurements, the model

392 parameters used in RAPID are presented, and flows computed are compared to observed

393 flows. Issues related to the time step used in RAPID and to the simulated wave celerities

394 are also presented.

395 4.1. Estimation of wave celerities

396 The USGS Instantaneous Data Archive (http://ida.water.usgs.gov/ida/) provides 15-

397 minute flow data that can be used to determine the flow wave celerity. Data at fifteen

398 gaging stations within the two basins studied are obtained from IDA over two time

399 periods (01 January 2004 - 30 June 2004 and for 01 January 2007 - 30 June 2007). The

400 maximum lagged cross-correlation between hydrographs at two consecutive gaging

401 stations is used to determine the flow wave celerity. The lagged cross-correlation $\rho$ is a

402 measure of similarity between two wave forms as a function of a lag time $\tau_{\text {lag }}$ applied to

403 one of them, as shown in Equation (15).

404

405

$$
\rho=\frac{\sum\left(Q^{a}(t)-\overline{Q^{a}}\right) \cdot\left(Q^{b}\left(t+\tau_{\text {lag }}\right)-\overline{Q^{b}}\right)}{\sqrt{\sum\left(Q^{a}(t)-\overline{Q^{a}}\right)^{2} \cdot \sum\left(Q^{b}\left(t+\tau_{\text {lag }}\right)-\overline{Q^{b}}\right)^{2}}}
$$


407 where $Q^{a}$ and $Q^{b}$ are the flows measured at the upstream and downstream station,

408 respectively; and the summation is here made every 15 minutes for 6 months. Figure 6

409 shows the correlation as a function of increasing lag time between three different sets of

410 consecutive gaging stations. The lag time giving the maximum correlation is taken as the

411 travel time $\tau_{\text {travel }}$ for the flow wave between the two stations. The travel times are

412 estimated for eleven sets of two stations and are shown on Table 1. Travel times of $0 \mathrm{~s}$

413 are reported at two stations, where the flow wave is probably too fast to be captured by

414 15-minute measurements. The wave celerity $\mathrm{c}$ is then computed using Equation (16)

$$
c=\frac{d}{\tau_{\text {travel }}}
$$

418 where $d$ is the distance between two stations. The NHDPlus Flow Table Navigator Tool

419 (http://www.horizon-systems.com/nhdplus/tools.php) is used to estimate the curvilinear

420 distance between two stations along the NHDPlus river network that are shown on Table

421 1. The wave celerity has been estimated for eleven sub-basins within the Guadalupe and

422 San Antonio river basins. Table 2 shows the values that are obtained for the two time

423 periods considered, as well as their average. Figure 7 shows the corresponding sub-

424 basins as well as the locations of all gaging stations.

\section{4.2. Parameters used in RAPID}

426 RAPID needs two vectors of parameters $\mathbf{k}$ and $\mathbf{x}$ that can either be determined using 427 physically-based equations, through optimization, or a combination of both. In this 428 study, daily stream flow data are obtained from the USGS National Water Information 
429 System (http://waterdata.usgs.gov/nwis) in order to use the built-in parameter estimation.

430 Within the Guadalupe and San Antonio river basins, NWIS has 74 gages that measure

431 flow, 36 of them having full records of daily measurements the four years studied (01

432 January 2004 - 31 December 2007). These 36 stations are used for parameter estimation.

433 Four sets of model parameters - denoted by the superscripts $\alpha, \beta, \gamma$ and $\delta$-are used in

434 this study. These sets of parameters are all based on Equation (14) which is used with a

435 uniform wave celerity of $c^{0}=1 \mathrm{~km} \cdot \mathrm{h}^{-1}=0.28 \mathrm{~m} \cdot \mathrm{s}^{-1}$ throughout the basin or with the

436 celerities $c_{j}$ determined based on the IDA lagged cross-correlation study.

437 The first set, $\left(\mathbf{k}^{\boldsymbol{\alpha}}, \mathbf{x}^{\boldsymbol{\alpha}}\right)$ is obtained from parameter estimation shown in Equation (11) using

438 the uniform wave celerity $c^{0}=0.28 \mathrm{~m} \cdot \mathrm{s}^{-1}$ and the resulting values of the two multiplying

439 factors $\lambda_{k}$ and $\lambda_{x}$ of Equation (14) are:

440

441

$$
\begin{array}{ll}
k_{j}^{\alpha}=\lambda_{k}^{\alpha} \cdot \frac{L_{j}}{c^{0}} \quad, \quad x_{j}^{\alpha}=\lambda_{x}^{\alpha} \cdot 0.1 \\
\lambda_{k}^{\alpha}=0.131042, & \lambda_{x}^{\alpha}=2.58128
\end{array}
$$

443 The parameters $\left(\mathbf{k}^{\boldsymbol{\beta}}, \mathbf{x}^{\boldsymbol{\beta}}\right)$ are determined without optimization using the celerities

$444 c_{j}$ determined based on the IDA lagged cross-correlation study and set to:

$$
\begin{array}{ll}
k_{j}^{\beta}=\lambda_{k}^{\beta} \cdot \frac{L_{j}}{c_{j}} & , \quad x_{j}^{\beta}=\lambda_{x}^{\beta} \cdot 0.1 \\
\lambda_{k}^{\beta}=1 & , \quad \lambda_{x}^{\beta}=1
\end{array}
$$


448 The third set of parameters $\left(\mathbf{k}^{\gamma}, \mathbf{x}^{\gamma}\right)$ is obtained through optimization using the celerities

$449 c_{j}$ determined based on the IDA lagged cross-correlation study and the resulting values 450 are:

$$
\begin{array}{ll}
k_{j}^{\gamma}=\lambda_{k}^{\gamma} \cdot \frac{L_{j}}{c_{j}} \quad, & x_{j}^{\gamma}=\lambda_{x}^{\gamma} \cdot 0.1 \\
\lambda_{k}^{\gamma}=0.617188, & \lambda_{x}^{\gamma}=1.95898
\end{array}
$$

454 The optimization converges to a value of $\mathbf{k}$ that is $38 \%$ smaller than that estimated with 455 the IDA lagged cross-correlation, suggesting that a faster flow wave in the river network 456 produces better flow calculations. In the present study, routing on the land surface from 457 the catchment to its corresponding reach is not modeled. Therefore, one would expect 458 that the optimized flow celerity in the river network would be slower than that estimated 459 from river flow observations, which is not the case here. This suggests that runoff is 460 either produced too slowly or too far upstream of each gage; maybe because runoff in

461 land surface models is often calibrated based on a lumped value at the downstream gage

462 of a basin, as was done here with Noah-MP. Further details on the quality of runoff

463 simulations are given in Section 4.4.

464 The fourth set of parameters $\left(\mathbf{k}^{\mathbf{\delta}}, \mathbf{x}^{\mathbf{\delta}}\right)$ is determined for a better match of celerity 465 calculations, as explained later in this paper.

\section{4.3. Time step of RAPID simulation}


467 Cunge [1969] showed that the Muskingum method is stable for any $x \in[0,0.5]$ and that

468 the wave celerity computed by the Muskingum method approaches the theoretical wave

469 celerity of the kinematic wave equation if the time step of the river routing equals the

470 travel time of the wave (for $x=0.5$ ), as shown in Equation (20):

471

472

$$
\forall j \in[1, m] \quad c_{j} \simeq \frac{L_{j}}{\Delta t}
$$

474 However, both the celerity of flow and the length of river reaches vary along the network;

475 and the model formulation of RAPID allows for only one unique value of the time step

$476 \Delta t$ be chosen. In the Guadalupe and San Antonio River Basins, the mean length is $3 \mathrm{~km}$

477 and the median length is $2.4 \mathrm{~km}$. The probability density function and the cumulative

478 density functions for the lengths of river reaches are shown in Figure 8. The celerities

479 estimated earlier are on the order of $c=2.5 \mathrm{~m} \cdot \mathrm{s}^{-1}$. Using the median value of the reach

480 length along with $c=2.5 \mathrm{~m} \cdot \mathrm{s}^{-1}$, Equation (20) gives $\Delta t=960 \mathrm{~s}$. In order to have an

481 integer conversion between the river routing time step and the land surface model time

482 step ( 3 hours), a value of $\Delta t=900 \mathrm{~s}=15 \mathrm{~min}$ is chosen.

483 4.4. Analysis of the quality of river flow computation

484 For various model simulations, the average and the root mean square error (RMSE) of

485 computed flow rate are calculated using daily data and are given in Table 3. The Nash

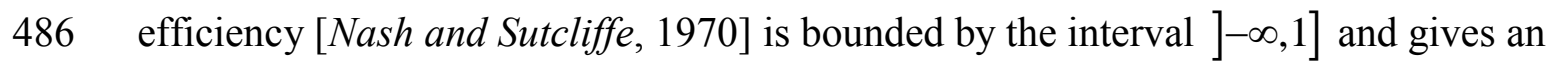

487 estimate of the quality of modeled river flow computations when compared to 
488 observations; and is also given in Table 3. An efficiency of 1 corresponds to a perfect

489 model and 0 corresponds to a model producing the mean of observations. The results

490 shown for a lumped model correspond to when runoff from Noah is accumulated at the

491 gage directly without any routing. The average values of flow in RAPID simulations are

492 tied to the amount of runoff water calculated by the Noah LSM and the bias generated by

493 the land surface model cannot be fixed by RAPID. However, the internal connectivity of

494 the NHDPlus river network is well translated in RAPID and mass is conserved within

495 RAPID since the flow rates in the lumped simulation and in all four simulations of

496 RAPID are the same. Figure 9 shows the ratio between observed and lumped stream

497 flow at 17 gages located across the Guadalupe and San Antonio River Basins. This ratio

498 is around unity downstream of the Guadalupe and San Antonio Rivers, but is greater than

4997 upstream; suggesting that runoff is most likely overestimated at the center of the basin.

500 Additionally, runoff is largely underestimated at two stations just downstream of the

501 outcrop area of the Edwards Aquifer: the Comal River at New Braunfels and the San

502 Marcos River at San Marcos. These stations measure large average stream flow

503 (respectively $10.59 \mathrm{~m}^{3} / \mathrm{s}$ and $5.9 \mathrm{~m}^{3} / \mathrm{s}$ ) although draining a relatively small area

504 (respectively $336 \mathrm{~km}^{2}$ and $129 \mathrm{~km}^{2}$ ), and are actually two of the largest springs in Texas.

505 These flows are much larger than the lumped runoff (respectively $0.67 \mathrm{~m}^{3} / \mathrm{s}$ and 0.26

$506 \mathrm{~m}^{3} / \mathrm{s}$ ), which is expected because the modeling framework presented herein does not does

507 not explicitly simulate aquifers.

508 However, the RAPID simulations $\left(\mathbf{k}^{\boldsymbol{\alpha}}, \mathbf{x}^{\boldsymbol{\alpha}}\right),\left(\mathbf{k}^{\boldsymbol{\beta}}, \mathbf{x}^{\boldsymbol{\beta}}\right)$ and $\left(\mathbf{k}^{\gamma}, \mathbf{x}^{\gamma}\right)$ lead to a smaller RMSE

509 and a higher Nash Efficiency than the lumped runoff. This shows that an explicit river 
510 routing scheme with carefully-chosen parameters allows obtaining better stream flow

511 calculations than a simple lumped runoff scheme, as expected.

512 Within the different RAPID simulations, the set of parameters $\left(\mathbf{k}^{\gamma}, \mathbf{x}^{\gamma}\right)$ gives the best

513 results for RMSE and Nash efficiency, followed by $\left(\mathbf{k}^{\boldsymbol{\beta}}, \mathbf{x}^{\boldsymbol{\beta}}\right),\left(\mathbf{k}^{\alpha}, \mathbf{x}^{\alpha}\right)$ and $\left(\mathbf{k}^{\boldsymbol{\delta}}, \mathbf{x}^{\boldsymbol{\delta}}\right)$.

514 Therefore, a greater spatial variability in the values of $k$ contributes to the quality of

515 model results, and the built-in optimization in RAPID further enhances these model

516 results. An example hydrograph for the Guadalupe River near Victoria TX is shown in

517 Figure 10, and is computed using $\left(\mathbf{k}^{\gamma}, \mathbf{x}^{\gamma}\right)$.

518 4.5. Comparison between estimated and computed wave celerities

519 In order to assess the capacity of the modeling framework to reproduce surface flow

520 dynamics, the celerity of the flow wave in outputs from RAPID are computed. Fifteen-

521 minute river flow is computed with RAPID, and the lagged cross-correlation presented

522 earlier is used to calculate the wave celerity within the RAPID simulation. Table 2 shows

523 the celerities that are computed from RAPID outputs. In the first three sets of model

524 parameters used, the wave celerities simulated in RAPID are greater than those observed.

525 One can also notice than even for $\left(\mathbf{k}^{\boldsymbol{\beta}}, \mathbf{x}^{\mathbf{\beta}}\right)$, the model-simulated celerities are different

526 than the observed celerities which are used to determine the vector $\mathbf{k}^{\beta}$ itself. This was

527 predicted by Cunge [1969] who showed that the difference between the celerity of the

528 kinematic wave equation and that computed using the Muskingum method is a function

529 of both $x$ and the quotient $\Delta t / L_{j}$. Only the specific values $x=0.5$ and $\Delta t$ verifying

$530 \Delta t / L_{j}=c_{j}$ allow obtaining the same celerity. Furthermore, the work herein is done in a 
531 river network, and the celerity estimated between two points does not correspond only to

532 the main river stem but rather to a combination of all river reaches present in the network

533 in between the two points. The ratio of the average celerities from RAPID using

$534\left(\mathbf{k}^{\boldsymbol{\beta}}, \mathbf{x}^{\boldsymbol{\beta}}\right)$ over the average observed celerities is 1.54. As a final experiment, a new set of 535 parameters $\left(\mathbf{k}^{\boldsymbol{\delta}}, \mathbf{x}^{\boldsymbol{\delta}}\right)$ is created to account for the faster waves in RAPID.

$$
\begin{array}{ll}
k_{j}^{\delta}=\lambda_{k}^{\delta} \cdot \frac{L_{j}}{c_{j}} \quad, & x_{j}^{\delta}=\lambda_{x}^{\delta} \cdot 0.1 \\
\lambda_{k}^{\delta}=1.54 \quad, \quad \lambda_{x}^{\delta}=1
\end{array}
$$

539 Table 2 shows that the parameters $\left(\mathbf{k}^{\boldsymbol{\delta}}, \mathbf{x}^{\boldsymbol{\delta}}\right)$ allow for wave celerities that are closer to the

540 observed ones than the celerities obtained with the other sets of parameters. The average

541 flow wave celerity over the 11 calculations in RAPID is within 3\% of that estimated with

542 IDA flows. Unfortunately, these closer wave celerities also lead to a decrease in the

543 quality of RMSE and Nash Efficiency. Therefore, model celerities closer to celerities

544 estimated from observations can be obtained, but generally deteriorate other statistics of

545 calculations. Again, this might be due to runoff being produced too slowly or too far

546 upstream of each gage.

\section{$547 \quad 4.6$ Potential improvement of spatial variability in RAPID parameters}

548 In the work presented here, the parameter $x$ is spatially and temporally constant over the

549 modeling domain and the parameter $k$ is temporally constant but varies at the river reach

550 level based on the length of each reach and on the celerity of the flow wave going 
551 through it. Flow wave celerities are estimated for 11 sub-basins based on flow

552 observations and the spatial variability of $k$ presented in this study is therefore partly

553 limited by the size of the sub-basins used for flow wave estimation. However such an

554 approach for computation of RAPID parameters allows taking into account wave

555 celerities that are estimated based on observations made at high temporal resolution as

556 well as verifying the modeling framework through reproduction of estimated wave

557 celerities. In a separate study applying RAPID to all rivers of Metropolitan France,

558 David et al. [2011] present a physically-based formulation of $k$ and a sub-basin

559 optimization for both $k$ and $x$, therefore allowing further spatial variability of

560 parameters. David et al. [2011] show that using a combination of reach length, river bed

561 slope and basin residence time for the parameter $k$ and applying the optimization

562 procedure to sub-basins both improve the efficiency and the RMSE of RAPID flow

563 computations. Such work could be adapted to the study herein based on information

564 provided in the NHDPlus dataset - for example reach length, mean annual flow velocity

565 and river bed slope - which would be advantageous when applying RAPID to domains

566 larger than the Guadalupe and San Antonio River Basins where estimation of wave

567 celerities everywhere may require excessive amounts of computations.

\section{$568 \quad 4.7$ Statistical Significance}

569 Changes in the routing procedure - i.e. no routing or routing using various RAPID

570 parameters - lead to various changes in the values of efficiency and RMSE, as shown in

571 Section 4.2. The statistical significance of the changes can be assessed in order to

572 determine whether or not various routing experiments are effective. For two different

573 routing procedures used, the efficiency (respectively RMSE) at one gage can be 
574 compared to the efficiency (respectively RMSE) at the same gage, although variability of

575 efficiency (respectively RMSE) between independent gages can be large. Therefore,

576 there is a logical pairing of efficiency and RMSE calculated at a given gage between two

577 experiments and hence matched pair tests are appropriate to assess the statistical

578 significance. Several common options are available for matched pair tests (with

579 increasing level of complexity): the sign test, the Wilcoxon signed-ranked test [Wilcoxon,

$5801945]$ and the paired t-test. The sign test has no assumption on the shape of probability

581 distributions of samples used but is quite simple since only the sign of differences

582 between two paired samples is accounted for. The Wilcoxon signed-ranks test

583 incorporates the magnitude of differences between paired samples under the assumption

584 that differences between pairs are symmetrically distributed. The paired t-test may be

585 used when the differences between pairs are known to be normally distributed. The

586 assumption of the Wilcoxon signed-ranks test (symmetry) is not as restrictive as that of

587 the paired t-test (normality). In case where small sample sizes are used - as done in this

588 study - testing for symmetry or normality may not be meaningful. Additionally,

589 violations of the symmetry assumption in the Wilcoxon signed-ranks test have minimal

590 influence on the corresponding p-values [Helsel and Hirsch, 2002]. These two reasons

591 motivate the use of the Wilcoxon signed-ranks test in the study herein. The null

592 hypothesis $H_{0}$ for this test is that the median of differences between two populations is

593 zero. The purpose of changes in the routing procedure being to improve results by

594 increasing the efficiency and decreasing the RMSE, alternate hypotheses can assume that

595 one population tends to be generally either larger $\left(H_{1}\right)$ or smaller $\left(H_{2}\right)$ than the other. 
596 Therefore, p-values corresponding to one-sided tests are used in this study. Low

597 significance levels mean that $H_{0}$ is unlikely, hence that a significant change is observed.

598 The Wilcoxon signed-ranks test sorts pairs with nonzero difference based on the absolute

599 value of the differences and sums all positive (respectively negative) ranks in a variable

600 named $W^{+}$(respectively $W^{-}$). The corresponding p-values vary with the number of

601 nonzero differences and with the value of $W^{+}$and $W^{-}$. Fortran programs were created to

602 compute the exact value of the test statistic (not using a large-sample approximation) as

603 well as the corresponding p-values. Table 4 shows the results of the Wilcoxon signed-

604 ranks test for both efficiency and RMSE and for several paired experiments using two

605 different routing procedures. The same 15 stations named on Figure 7 and used in Table

6063 serve here for statistical significance assessment and the corresponding 15 values of

607 efficiency and of RMSE are utilized as sample values.

608 Several conclusions can be drawn from Table 4. First, the Wilcoxon signed-ranks tests

609 comparing results obtained by RAPID with parameters $\alpha, \beta$ and $\gamma$ to a lumped runoff

610 approach show that the null hypothesis can be rejected for a one-sided test at a $10 \%$ level

611 of significance in all cases, except for the efficiency between RAPID with $\beta$ parameters

612 and a lumped approach at a $13 \%$ level of significance. All these tests validate that the

613 improvements mentioned in Section 4.2 (increased efficiency and decreased RMSE) are

614 statistically significant and confirm that an explicit river routing scheme allows obtaining

615 better stream flow calculations than a simple lumped runoff scheme, as expected.

616 Second, comparisons between RAPID using $\alpha$ and $\gamma$ parameters show that sub-basin

617 variability in wave celerities is advantageous to a spatially uniform wave celerity 
618 approach at a 19\% level of significance for efficiency and at a 7\% level for RMSE.

619 Third, comparisons between RAPID using $\gamma$ and $\delta$ parameters confirms that wave

620 celerities close to those determined from observations deteriorate results at a $3 \%$ level of

621 significance for both efficiency and RMSE. Finally, one cannot conclude on the

622 statistical significance of the comparison between RAPID using $\beta$ and $\gamma$ parameters

623 concerning the improvement of optimization procedure. However, since RAPID

624 using $\gamma$ parameters produce better average values than RAPID using $\beta$ parameters and

625 since the statistical significance of RAPID using $\gamma$ parameters compared to a lumped

626 approach is better than that of RAPID using $\beta$ parameters compared to lumped approach,

627 the optimization can still considered advantageous.

628

629 
630 5. Synthetic study of the Upper Mississippi River Basin, speedup of parallel

\section{1 computations}

632 Through the use of mathematical and optimization libraries that run in a parallel

633 computing environment, RAPID can be applied on several processing cores. The work

634 presented above focuses on the Guadalupe and San Antonio River basins together

635 forming a river network with 5,175 river and water body reaches, which size do not

636 justify the use of parallel computing. However, all the tools and datasets used are

637 available for the Contiguous United States where the NHDPlus dataset has about 3

638 million reaches. Adapting the proposed framework to simultaneously compute flow and

639 volume of water in all mapped water bodies of the contiguous United States would

640 require solving matrix equations of size 3 million. For such a large scientific problem,

641 parallel computing can be helpful if speedup can be achieved, i.e. if increasing the

642 number of processing cores decreases the total computing time.

\section{$643 \quad 5.1$ Synthetic study used for assessment of parallel performance}

644 As a proof of concept, the evaluation of the parallel computing capabilities of RAPID is 645 presented here using the Upper Mississippi River Basin (shown on Figure 3) which has

646182,240 river and water body reaches available as Region 07 in the NHDPlus dataset.

647 The number of computational elements for the Upper Mississippi River Basin is about 35

648 times larger than the combination of the Guadalupe and San Antonio River Basins, and

649 about 16 times smaller than the entire Contiguous United States. The river network of

650 the Upper Mississippi River Basin is fully interconnected, all water eventually flowing to 651 a unique outlet. 
652 In order to assess the performance of RAPID, the same problem consisting in the

653 computation of river flow in all reaches of the Upper Mississippi River Basin, over 100

654 days, at a 900-second time step is solved for all results reported in Section 5.3. For this

655 performance study, the runoff data symbolized by vector $\mathbf{Q}^{\mathbf{e}}$ in Equation (1) are

656 synthetically generated and set to $1 \mathrm{~m}^{3}$ every 3 hours for all reaches and all time steps

657 and the vectors of parameters $\mathbf{k}$ and $\mathbf{x}$ are temporally and spatially uniform as shown in 658 Equation (22):

659

660

$$
k_{j}=\frac{L_{j}}{2.5 m \cdot s^{-1}} \quad, \quad x_{j}=0.3
$$

\section{$662 \quad 5.2$ Basics of solving a linear system on computers}

663 Numerically solving a linear system is typically an iterative process mainly involving

664 two-steps at each iteration: preconditioning followed by applying a linear solver.

665 Preconditioning is a procedure that transforms a given linear system through matrix

666 multiplication into one that is more easily solved by linear solvers, hence decreasing the

667 total number of iterations to find the solution and saving time. If the linear system is

668 triangular, preconditioning is sufficient to solve the problem, and a linear solver is not

669 needed. In a parallel computing environment, a matrix is separated into diagonal and off-

670 diagonal blocks, each processing core being assigned one diagonal block and its adjacent

671 off-diagonal block. Solving a linear system in parallel is made using blocks and parallel

672 preconditioning is determined based on elements in the diagonal blocks. Preconditioning

673 is sufficient to solve a given parallel linear system if the system is diagonal by blocks - 
674 i.e. all off-diagonal blocks are empty - and if each diagonal block is triangular; in most

675 other cases iterations of preconditioning and applying a linear solver are needed.

\section{$676 \quad 5.3$ Parallel speedup of the synthetic study}

677 For comparison purposes, the traditional Muskingum method was also implemented in

678 RAPID in order to assess the performance of the matrix-based Muskingum method

679 developed herein. Figure 11 shows a comparison of computing time between the

680 traditional Muskingum method shown in Equation (4) and applied consecutively from

681 upstream to downstream and the Matrix-based Muskingum method used in RAPID.

682 Only one processor in used for all results in Figure 11 but the computation method

683 differs. The matrix $\mathbf{I}-\mathbf{C}_{\mathbf{1}} \cdot \mathbf{N}$ being triangular (see Appendix B), solving the linear

684 system of Equation (1) can be limited to matrix preconditioning if using only one

685 processing core. In a parallel computing environment, $\mathbf{I}-\mathbf{C}_{\mathbf{1}} \cdot \mathbf{N}$ is separated in blocks,

686 each diagonal block corresponding to a sub-basin. With several processing cores, matrix

687 preconditioning would be sufficient to solve Equation (1) if $\mathbf{I}-\mathbf{C}_{\mathbf{1}} \cdot \mathbf{N}$ could be made

688 diagonal by blocks, each diagonal block being a triangular matrix. In a river network that

689 is fully interconnected such as that of the Upper Mississippi River Basin $\mathbf{I}-\mathbf{C}_{\mathbf{1}} \cdot \mathbf{N}$

690 cannot be made diagonal by blocks because the connectivity between adjacent sub-basins

691 would always appear as an element in an off-diagonal block matrix (cf. Equation (23)

692 when $i$ and $j$ are connected but belong to different sub-basins). This limitation would

693 not apply if one was to compute the Mississippi River basin on one (or on one set of)

694 processing core(s) and the Colorado River Basin on another (or on another set of)

695 processing core(s) for example. Therefore, when solving Equation (1) on several 
696 processing cores for the Upper Mississippi River Basin, preconditioning is not sufficient

697 and iterative methods need be used. An iterative method implies several computations

698 including preconditioning, matrix-vector multiplication and calculation of residual norm

699 at each iteration.

700 On one processing core, solving the matrix-based Muskingum method with

701 preconditioning only is about twice as long as solving the traditional Muskingum method,

702 as shown in Figure 11. This extra time can be explained because the computation of the

703 right-hand-side of Equation (1) is approximately as expensive as solving the traditional

704 Muskingum method and approximately as expensive as preconditioning. However, the

705 computation of the right-hand-side is done only once per time step regardless of the

706 number of iterations if using an iterative linear solver and scales very well because all

707 operations require no communication except for the product $\mathbf{N} \cdot \mathbf{Q}$ which involves little

708 communication. Figure 11 also shows the computing time when using an iterative solver.

709 The sole purpose of the first iteration in an iterative solver is to determine an initial

710 residual error that is to be used as a criterion for convergence in following iterations.

711 This first iteration mainly involves preconditioning and calculation of a residual norm.

712 On one processing core only, the second iteration converges because preconditioning is

713 sufficient. The two iterations and calculations of norms explain the doubling of

714 computing time between preconditioning only and an iterative solver on one unique

715 processing core that is shown in Figure 11. Overall, the overhead created by an iterative

716 solver over the traditional Muskingum method is about a factor of four. Again, both

717 preconditioning and calculation of residual norms scale well although the latter can be

718 limited by communications. Therefore, the main issue with using a matrix method is the 
719 number of iterations needed before the iterative solver converges because all other

720 overhead dissipates with an increasing number of processing cores used. Surprisingly,

721 the number of iterations needed for the iterative solver to converge increases much less

722 quickly than the number of processing cores used, hence allowing to gain total

723 computation time with increased number of processing cores and to produce results faster

724 than the traditional Muskingum method as shown on Figure 12. This suggests that even

725 in a basin where all river reaches are interdependent, some upstream and downstream

726 sub-basins can be computed separately in an iterative scheme given that they are distant

727 enough from each other. The physical explanation is that flow waves are not fast enough

728 to travel across the entire basin within one 15-minute time step. This de-coupling of

729 computations could not be achieved by using the traditional version of the Muskingum

730 method, since computations are not iterative and have to be performed going from

731 upstream to downstream. Figure 12 shows that the total computing time with an iterative

732 matrix solver on 16 processing cores is almost a third of the time needed by the

733 traditional Muskingum method and keeps decreasing further with more processing cores.

734 However, as the number of cores increase, the relative importance of the computation of

735 residual norms within the iterative solver increases up to taking almost half of the solving

736 time, as shown in Figure 12. This limitation will most likely disappear as computer

737 technology advances and communication time decreases. One should note that the output

738 files match on a byte-to-byte basis and hence model computations are strictly the same

739 regardless of the method used; i.e. traditional Muskingum method or Matrix-based

740 Muskingum method, iterative or not. This strict similarity between output files and the

741 slow increase in iterations are also verified for the study of the Guadalupe and San 
742 Antonio River Basins presented above; hence the use of synthetic data and simplified

743 model parameters does not influence the trends in speedup.

744 Computing loads are balanced for all simulations in this study, i.e. the number of river

745 reaches assigned to each processing core is almost identical across cores. Figure 13

746 shows how sub-basins of the Upper Mississippi River Basin are divided among

747 processing cores as well as the longest river path of the basin. The longest path goes

748 through 8 sub-basins on 8 cores, and 14 sub-basins on 16 cores. If one were to apply the

749 traditional Muskingum method on several processing cores with the division in sub-

750 basins shown in Figure 13, computations would have to be made sequentially from

751 upstream to downstream, each core having to wait for its upstream core to be done prior

752 to starting its work. Hence, assuming that the total computing time can be evenly divided

753 by the total number of nodes and neglecting communication overhead, one could only

754 hope to decrease computing time by a factor of $8 / 8=1$ (no gain) for 8 cores and by a

755 factor of $16 / 14=1.14$ for 16 cores. The iterative matrix solver provides much better

756 results (a decrease by a factor of 2.90 for 16 cores).

757 River flow is a causal phenomenon that mainly goes downstream. Therefore, when using

758 an upstream-to-downstream computation scheme and unless dealing with completely

759 separated river basins, one cannot expect to obtain perfect speedup i.e. decreasing of

760 computing time by a factor equal to the number of cores. However, today's

761 supercomputers having tens of thousands of computing cores, one could leverage such

762 power to save human time. Additionally, the matrix method developed here can be

763 directly applied to a combination of independent river basins in which case speedup

764 would be ideally perfect. Furthermore, matrix methods such as the one developed here 
765 could be adapted to more complex river flow equations - like variable-parameter

766 Muskingum methods or schemes allowing for backwater effects - in order to save total

767 computing time. Finally, the splitting up into sub-basins used here is very simple and

768 optimizing this partition by limiting connections between sub-basins or taking into

769 account flow wave celerities relatively to basin sizes could respectively help limit the

770 number of communications and the number of iterations in the linear system solver. 


\section{Conclusions}

773 NHDPlus is a GIS dataset that describes the networks of mapped rivers and water bodies

774 of the United States. One of the main advantages of NHDPlus is that connectivity

775 information for the river networks is available. Therefore, this dataset offers possibilities

776 for the development of river routing models that simultaneously calculate flow and

777 volume of water in all water bodies of the nation. Furthermore, the USGS National

778 Water Information System has thousand of gages located on the NHDPlus network which

779 can be used to assess the quality of such river models across river basins (not only at

780 basin outlets). The research presented in this paper investigates how to develop a river

781 network model using NHDPlus networks and how to assess model computations and

782 optimize model parameters with USGS stream flow measurements. All tools and

783 datasets used herein are available for the contiguous United States, but this research

784 addresses two smaller domains. The combination of the Guadalupe and San Antonio

785 River Basins in Texas is used in a 4-year case study, and the Upper Mississippi River

786 Basin is used in a speedup study with synthetic data. Graph theory is applied to a river

787 network to create a network matrix that is used to develop a vector-matrix version of the

788 Muskingum method and applied in a new river network model called RAPID. It has been

789 shown that a GIS-based hydrographic dataset can be used as the river network for a river

790 model to compute flow in large networks of thousands of reaches, including ungaged

791 locations. A simple flux coupler for connecting a land surface model with an NHDPlus

792 river network is presented. No horizontal routing of flow from the land surface to the

793 river network is used in this study, and such an addition would help improve model

794 calculations. An inverse method is developed to estimate model parameters in RAPID 
795 using available gage measurements located across the river basins. Wave celerities are

796 estimated in several locations of the basin studied. RMSE and Nash efficiency of

797 computed flow rates in four RAPID simulations are compared with a basic lumped model

798 where runoff is directly accumulated at the gage, with gage measurements and among

799 themselves. RAPID produces better RMSE and Nash efficiency than the lumped model

800 and the improvements are statistically significant. Although the quality of RAPID

801 calculations is tied to the quantity of runoff generated by the land surface model that

802 provides runoff, mass is conserved within RAPID since the average flow rate is

803 conserved. Spatial variability of parameters enhances the RMSE and Nash efficiency of

804 RAPID calculations. Wave celerities are reproduced within a few percents with the

805 model proposed, although wave celerities closer to those estimated from gage data

806 generally deteriorate the other statistics of calculations. This deterioration might be due

807 to runoff being produced too slowly or too far upstream of each gage. The parameters

808 used in this study are simple, but could be improved based on information available in

809 NHDPlus such as slope, mean flow and velocity of all reaches or by using modified

810 versions of the Muskingum method with time-variable parameters although the latter

811 would necessitate modification of the optimization procedure developed herein. The

812 matrix formulation in RAPID can be transferred in a parallel computing environment. A

813 synthetic study of the Upper Mississippi River Basin shows that although a large initial

814 overhead is added by the matrix method, this overhead decreases with increasing number

815 of processing cores. More importantly, an iterative matrix solver allows de-coupling of

816 sub-basins - even if the main river basin is fully interconnected - hence permitting

817 computation of sub-basins separately if they are distant enough from each other. As 
818 consequence, while producing the exact same results as the traditional Muskingum

819 method, the matrix-based Muskingum method decreases the total computing time when

820 run on several processing cores. Such a gain in computing time would be highly

821 beneficial if addressing larger scales, like the entire Contiguous United States which

822 would represent a square matrix of size 3 million.

823 


\section{Acknowledgements}

825 This work was partially supported by the U.S. National Aeronautics and Space

826 Administration under the Interdisciplinary Science Project NNX07AL79G, by the U.S.

827 National Science Foundation under project EAR-0413265: CUAHSI Hydrologic

828 Information Systems, by Ecole des Mines de Paris, France, and by the American

829 Geophysical Union under a Horton (Hydrology) Research Grant. The authors wish to

830 thank the PETSc and TAO developers, especially Dr. Barry Smith, Dr. Matthew

831 Knepley, Dr. Satish Balay and Dr. Jason Sarich for their continuous assistance

832 throughout the development of RAPID. Thank you to Dr. Karl Shultz from TACC for

833 his help regarding the handling of inputs and outputs on supercomputers. The computing

834 resources were provided by TACC, which is gratefully acknowledged. Thank you to Dr.

835 Stefano Orlandini for suggestions on an early version of this work. The authors are

836 thankful to the two anonymous reviewers and to the editor for their valuable comments

837 and suggestions that helped improved the original version of this manuscript. 838 


\section{Appendix A - Implementation of RAPID}

840 The river network routing model is coded in Fortran 90 using the Portable, Extensible

841 Toolkit for Scientific Computation (PETSc) mathematical library [Balay, et al., 1997;

842 Balay, et al., 2008; Balay, et al., 2009] and the Toolkit for Advanced Optimization

843 (TAO) optimization library [McInnes, et al., 2009]. PETSc can be used to create

844 matrices and vectors and to apply a variety of linear operations such as matrix-vector

845 multiplications or linear system solving. TAO offers multiple methods for unconstrained

846 and constrained optimization. Both PETSc and TAO are built upon the Message Passing

847 Interface [Dongarra, et al., 1994] - a standard for communications between processing

848 cores - and can seamlessly be run in a sequential or a parallel computing environment.

849 In this study, sparse matrices are stored using the sequential AIJ format when using one

850 processing core and the MPIAIJ format when using several cores. Linear systems are

851 solved within PETSc either by preconditioning only or with preconditioning associated to

852 a Richardson method. The preconditioning methods used herein are ILU on one

853 processing core, and bloc Jacobi on several cores. The optimization method used in TAO

854 is a line search algorithm called the Nelder-Mead method. The netCDF file format [Rew

855 and Davis, 1990] is utilized for both inputs and outputs. RAPID is run on single- and

856 multiple-processor workstations as well as on Lonestar

857 (http://www.tacc.utexas.edu/resources/hpcsystems/\#lonestar), a supercomputer running at

858 the Texas Advanced Computing Center (TACC). This Dell Linux Cluster has 1,460

859 nodes, each node with 8 GB of memory and with two dual-core sockets. Lonestar has a

860 total of 5,840 computing cores.

861 


\section{Appendix B - NHDPlus used in RAPID}

863 NHDPlus [USEPA and USGS, 2007] is a geographic information system (GIS) dataset

864 for the hydrography of the United States. This dataset provides the mapped streams and

865 rivers as well as the catchments that surround them. NHDPlus is based on the medium

866 resolution 1:100,000 scale national hydrographic dataset (NHD). One of the main

867 improvements in NHDPlus is the network connectivity available in the value added

868 attributes (VAA) table for the river network. Each NHDPlus reach in the national

869 network is assigned a unique integer identifier called COMID. NHDPlus catchments also

870 have a COMID, the same COMID being used for the reach and its local contributing

871 catchment. Nodes are located at the two ends of each NHDPlus river reach. A unique

872 integer identifier is given to all nodes in the national river reach network. The VAA table

873 includes FromNode and ToNode fields that give which node is upstream and which is

874 downstream of a given reach. Two reaches that are connected in a river network share a

875 node, and the reach $j$ flows into the reach $i$ if ToNode $(j)=$ FromNode $(i)$. The

876 NHDPlus connectivity between reaches, catchments and nodes is illustrated for three

877 catchments of the Guadalupe and San Antonio basins in Figure 14.

878 In its current formulation, RAPID can handle several upstream reaches but only one

879 unique downstream reach. However, divergences exist in mapped river networks, as they

880 do in NHDPlus. The VAA table offers a Divergence field to each of the river reaches

881 (with values of 0 - not part of a divergence, 1 - main path of a divergence, 2 - minor path

882 of a divergence). In the current formulation of RAPID, the main part of a divergence

883 carries all the upstream flow. The FromNode, ToNode and Divergence fields are used to 
884 populate the network matrix given in Equation (5), by means of the following logical 885 statement:

$887 \forall(i, j) \in[1, m]^{2}$, if $[$ FromNode $(i)=$ ToNode $(j)]$ and $[$ Divergence $(j) \neq 2] \Rightarrow N_{i, j}=1(23)$

889 where $N_{i, j}$ is the element of $\mathbf{N}$ located at row $i$ and column $j$. Therefore, upstream to

890 downstream connection is conserved if the downstream reach is the major branch of a

891 divergence or if it is not part of a divergence at all, but the connection is not made for a

892 minor branch of a divergence.

893 The VAA table also has information on the relative location - upstream or downstream -

894 of NHDPlus reaches. This information is available in a field called Hydroseq consisting

895 of a unique integer attributed to all NHDPlus reaches. Sorting the Hydroseq field in

896 decreasing order prior to computations guarantees that all upstream elements are

897 computed prior to solving the flow equations for any given river reach. This organization

898 of computations allows the matrix $\mathbf{I}-\mathbf{C}_{\mathbf{1}} \cdot \mathbf{N}$ of Equation (1) to be made lower triangular

899 which increases the ease and speed of solving this linear system.

900 


\section{References}

902 Apostolopoulos, T. K., and K. P. Georgakakos (1997), Parallel computation for 903 streamflow prediction with distributed hydrologic models, Journal of Hydrology, 197, 190424.

905 Balay, S., W. D. Gropp, L. C. McInnes, and B. F. Smith (1997), Efficient Management of 906 Parallelism in Object Oriented Numerical Software Libraries, in Modern Software Tools 907 in Scientific Computing, edited by E. A. a. A. M. B. a. H. P. Langtangen, pp. 163-202.

908 Balay, S., K. Buschelman, V. Eijkhout, W. D. Gropp, D. Kaushik, M. G. Knepley, L. C. 909 McInnes, B. F. Smith, and H. Zhang (2008), PETSc Users Manual (Revision 3.0.0), 1$910191 \mathrm{pp}$, Argonne National Laboratory.

911 Balay, S., K. Buschelman, W. D. Gropp, D. Kaushik, M. G. Knepley, L. C. McInnes, B. 912 F. Smith, and H. Zhang (2009), PETSc Web page, Available online at 913 http://www.mcs.anl.gov/petsc.

914 Berge, C. (1958), Matrice Associée d'un graphe, in Théorie des Graphes et ses 915 Applications, edited, pp. 126-128, Dunod, Paris.

916 Cunge, J. A. (1969), On the subject of a flood propagation computation method 917 (Muskingum method), Journal of Hydraulic Research, 7, 205-230.

918 David, C. H., D. J. Gochis, D. R. Maidment, W. Yu, D. N. Yates, and Z.-L. Yang (2009), 919 Using NHDPlus as the Land Base for the Noah-distributed Model, Transactions in GIS, 920 13, 363-377.

921 David, C. H., F. Habets, D. R. Maidment, and Z.-L. Yang (2011), RAPID applied to the 922 SIM-France model, Hydrological Processes, Accepted Article, doi: 10.1002/hyp.8070, 923 n/a-n/a.

924 De Roo, A., B. Gouweleeuw, and J. Thielen (2003), Development of a European flood forecasting system, International Journal of River Basin Management, 1, 49-59.

Dongarra, J., D. Walker, E. Lusk, B. Knighten, M. Snir, A. Geist, S. Otto, R. Hempel, E. Lusk, W. Gropp, J. Cownie, T. Skjellum, L. Clarke, R. Littlefield, M. Sears, S. Husslederman, E. Anderson, S. Berryman, J. Feeney, D. Frye, L. Hart, A. Ho, J. Kohl, P. Madams, C. Mosher, P. Pierce, E. Schikuta, R. G. Voigt, R. Babb, R. Bjornson, V. Fernando, I. Glendinning, T. Haupt, C. T. H. Ho, S. Krauss, A. Mainwaring, D. Nessett, S. Ranka, A. Singh, D. Weeks, J. Baron, N. Doss, S. Fineberg, A. Greenberg, D. Heller, G. Howell, B. Leary, O. McBryan, P. Pacheco, P. Rigsbee, A. Sussman, S. Wheat, E. Barszcz, A. Elster, J. Flower, R. Harrison, T. Henderson, J. Kapenga, A. Maccabe, P. McKinley, H. Palmer, A. Robison, R. Tomlinson, and S. Zenith (1994), Special Issue MPI - a Message-Passing Interface Standard, International Journal of Supercomputer Applications and High Performance Computing, 8, 159-416.

Fread, D. L. (1993), Flow Routing, in Handbook of Hydrology, edited by D. R. Maidment, pp. 10.17-10.18, McGraw-Hill, New York.

Gochis, D. J., and F. Chen (2003), Hydrological Enhancements to the Community Noah Land Surface Model, available online at http://www.ucar.edu/library/collections/technotes/technotes.jsp.

Guan, H., J. L. Wilson, and H. Xie (2009), A cluster-optimizing regression-based approach for precipitation spatial downscaling in mountainous terrain, Journal of Hydrology, 375, 578-588. 
945 Habets, F., J. Noilhan, C. Golaz, J. P. Goutorbe, P. Lacarrere, E. Martin, C. Ottle, and D.

946 Vidal-Madjar (1999a), The ISBA surface scheme in a macroscale hydrological model

947 applied to the Hapex-Mobilhy area - Part I: Model and database, Journal of Hydrology, $948 \quad 217,75-96$.

949 Habets, F., J. Noilhan, C. Golaz, J. P. Goutorbe, P. Lacarrere, E. Leblois, E. Ledoux, E. 950 Martin, C. Ottle, and D. Vidal-Madjar (1999b), The ISBA surface scheme in a 951 macroscale hydrological model applied to the Hapex-Mobilhy area - Part II: Simulation of streamflows and annual water budget, Journal of Hydrology, 217, 97-118.

Habets, F., P. Etchevers, C. Golaz, E. Leblois, E. Ledoux, E. Martin, J. Noilhan, and C. Ottle (1999c), Simulation of the water budget and the river flows of the Rhone basin, Journal of Geophysical Research-Atmospheres, 104, 31145-31172.

Habets, F., A. Boone, J. L. Champeaux, P. Etchevers, L. Franchisteguy, E. Leblois, E. Ledoux, P. Le Moigne, E. Martin, S. Morel, J. Noilhan, P. Q. Segui, F. RoussetRegimbeau, and P. Viennot (2008), The SAFRAN-ISBA-MODCOU hydrometeorological model applied over France, Journal of Geophysical ResearchAtmospheres, 113.

Helsel, D. R., and R. M. Hirsch (2002), Chapter A3. Statistical Methods in Water Resources, in Techniques of Water-Resources Investigations of the United States Geological Survey. Book 4, Hydrologic Analysis and Interpretation, edited, pp. 137-156, United States Geological Survey.

Jones, J. E., and C. S. Woodward (2001), Newton-Krylov-multigrid solvers for largescale, highly heterogeneous, variably saturated flow problems, Advances in Water Resources, 24, 763-774.

Kollet, S. J., and R. M. Maxwell (2006), Integrated surface-groundwater flow modeling: A free-surface overland flow boundary condition in a parallel groundwater flow model, Advances in Water Resources, 29, 945-958.

Kollet, S. J., R. M. Maxwell, C. S. Woodward, S. Smith, J. Vanderborght, H. Vereecken, and C. Simmer (2010), Proof of concept of regional scale hydrologic simulations at hydrologic resolution utilizing massively parallel computer resources, Water Resour. Res., 46, W04201.

Koussis, A. D. (1978), Theoretical Estimations of Flood Routing Parameters, J. Hydraul. Div. Am. Soc. Civ. Eng., 104, 109-115.

Larson, J. W., A. P. Craig, J. B. Drake, D. J. I. Erickson, M. Branstetter, and M. W. Ham (2007), A Massively Parallel Dynamical Core for Continental- to Global-Scale River Transport, paper presented at Proceedings of the International Congress and Modelling and Simulation (ModSim 2007).

Ledoux, E., G. Girard, G. de Marsily, J. P. Villeneuve, and J. Deschenes (1989), Spatially Distributed Modeling: Conceptual Approach, Coupling Surface Water and Groundwater, in Unsaturated Flow in Hydrologic Modeling Theory and Practice, edited by H. J. Morel-Seytoux, pp. 435-454, Kluwer Academic Publishers.

Lehner, B., K. Verdin, and A. Jarvis (2006), HydroSHEDS Technical Documentation, available online at http://hydrosheds.cr.usgs.gov.

Leopold, C., M. Süß, and J. Breitbart (2006), Programming for Malleability with Hybrid

989 Prognosis, paper presented at European Conference on Modelling and Simulation. 
Lohmann, D., E. Raschke, B. Nijssen, and D. P. Lettenmaier (1998a), Regional scale

991 hydrology: I. Formulation of the VIC-2L model coupled to a routing model, Hydrological

992 Sciences Journal-Journal Des Sciences Hydrologiques, 43, 131-141.

993 Lohmann, D., E. Raschke, B. Nijssen, and D. P. Lettenmaier (1998b), Regional scale

994 hydrology: II. Application of the VIC-2L model to the Weser River, Germany,

995 Hydrological Sciences Journal-Journal Des Sciences Hydrologiques, 43, 143-158.

996 Lohmann, D., K. E. Mitchell, P. R. Houser, E. F. Wood, J. C. Schaake, A. Robock, B. A.

997 Cosgrove, J. Sheffield, Q. Y. Duan, L. F. Luo, R. W. Higgins, R. T. Pinker, and J. D.

998 Tarpley (2004), Streamflow and water balance intercomparisons of four land surface

999 models in the North American Land Data Assimilation System project, Journal of

1000 Geophysical Research-Atmospheres, 109, 1-22.

1001 Maurer, E. P., G. M. O'Donnell, D. P. Lettenmaier, and J. O. Roads (2001), Evaluation of

1002 the land surface water budget in NCEP/NCAR and NCEP/DOE reanalyses using an off-

1003 line hydrologic model, Journal of Geophysical Research-Atmospheres, 106, 17841-

100417862.

1005 McCarthy, G. T. (1938), The Unit Hydrograph and Flood Routing, paper presented at

1006 Conference of the North Atlantic Division, U.S. Engineer Department, New London,

1007 Connecticut, on June 24, 1938.

1008 McInnes, L. C., J. Moré, T. Munson, and J. Sarich (2009), TAO User Manual (Revision

1009 1.10), 1-64 pp, Mathematics and Computer Science Division, Argonne National

1010 Laboratory, Available online at http://www.mcs.anl.gov/tao.

1011 Miller, W. A., and J. A. Cunge (1975), Simplified Equations of Unsteady Flow, in

1012 Unsteady Flow in Open Channels, edited by K. Mahmood and V. Yevjevich, pp. 216-

1013 232, Water Resources Publications, Fort Collins, CO.

1014 Nash, J. E., and J. V. Sutcliffe (1970), River flow forecasting through conceptual models

1015

1016

1017

part I -- A discussion of principles, Journal of Hydrology, 10, 282-290.

NERC (1975), Flood Routing Studies, in Flood Studies Report, edited, National

1018

1019

1020

1021

1022

1023

1024

1025

1026

1027

1028

1029

1030

1031

1032 Environment Research Council, London.

Niu, G. Y., Z. L. Yang, R. E. Dickinson, L. E. Gulden, and H. Su (2007), Development of a simple groundwater model for use in climate models and evaluation with Gravity Recovery and Climate Experiment data, Journal of Geophysical Research-Atmospheres, 112, 1-14.

Niu, G. Y., Z. L. Yang, K. E. Mitchell, F. Chen, M. Ek, M. Barlage, L. Longuevergne, A. Kumar, K. Manning, D. Niyogi, E. Rosero, M. Tewari, and Y.-L. Xia (2010), The Community Noah Land Surface Model with Multi-Physics Options, Journal of Geophysical Research-Atmospheres, (submitted).

Oki, T., Y. Agata, S. Kanae, T. Saruhashi, D. W. Yang, and K. Musiake (2001), Global assessment of current water resources using total runoff integrating pathways, Hydrological Sciences Journal-Journal Des Sciences Hydrologiques, 46, 983-995.

Olivera, F., J. Famiglietti, and K. Asante (2000), Global-scale flow routing using a source-to-sink algorithm, Water Resources Research, 36, 2197-2207.

Orlandini, S., and R. Rosso (1998), Parameterization of stream channel geometry in the distributed modeling of catchment dynamics, Water Resources Research, 34, 1971-1985. 
1033 Orlandini, S., G. Moretti, M. Franchini, B. Aldighieri, and B. Testa (2003), Path-based 1034 methods for the determination of nondispersive drainage directions in grid-based digital 1035 elevation models, Water Resources Research, 39.

1036 Ponce, V. M., and V. Yevjevich (1978), Muskingum-Cunge Method with Variable 1037 Parameters, J. Hydraul. Div. Am. Soc. Civ. Eng., 104, 1663-1667.

1038 Ponce, V. M. (1986), Diffusion Wave Modeling of Catchment Dynamics, J. Hydraul. 1039 Eng.-ASCE, 112, 716-727.

1040 Rew, R., and G. Davis (1990), Netcdf - an Interface for Scientific-Data Access, Ieee 1041 Computer Graphics and Applications, 10, 76-82.

1042 Solomon, S., D. Qin, M. Manning, Z. Chen, M. Marquis, K.B. Averyt, M. Tignor, and H. 1043 L. Miller (2007), Climate Change 2007: The Physical Science Basis. Contribution of 1044 Working Group I to the Fourth Assessment Report of the Intergovernmental Panel on 1045 Climate Change (IPCC), 996 pp., Cambridge University Press, Cambridge.

1046 Todini, E. (2007), A mass conservative and water storage consistent variable parameter 1047 Muskingum-Cunge approach (vol 11, pg 1645, 2007), Hydrology and Earth System 1048 Sciences, 11, 1783-1783.

1049 USEPA, and USGS (2007), NHDPlus User Guide, available online at 1050 http://www.horizon-systems.com/nhdplus/documentation.php.

1051 von Bloh, W., S. Rost, D. Gerten, and W. Lucht (2010), Efficient parallelization of a 1052 dynamic global vegetation model with river routing, Environmental Modelling \& 1053 Software, 25, 685-690.

1054 Wilcoxon, F. (1945), Individual Comparisons by Ranking Methods, Biometrics Bulletin, $1055 \quad 1,80-83$.

1056

1057 
Table 1 Travel time (s) for the flow waves estimated using the lagged cross-correlation in the Guadalupe and San

Antonio River Basins, both from IDA measurements and from RAPID model runs; and distance (km) between gaging stations

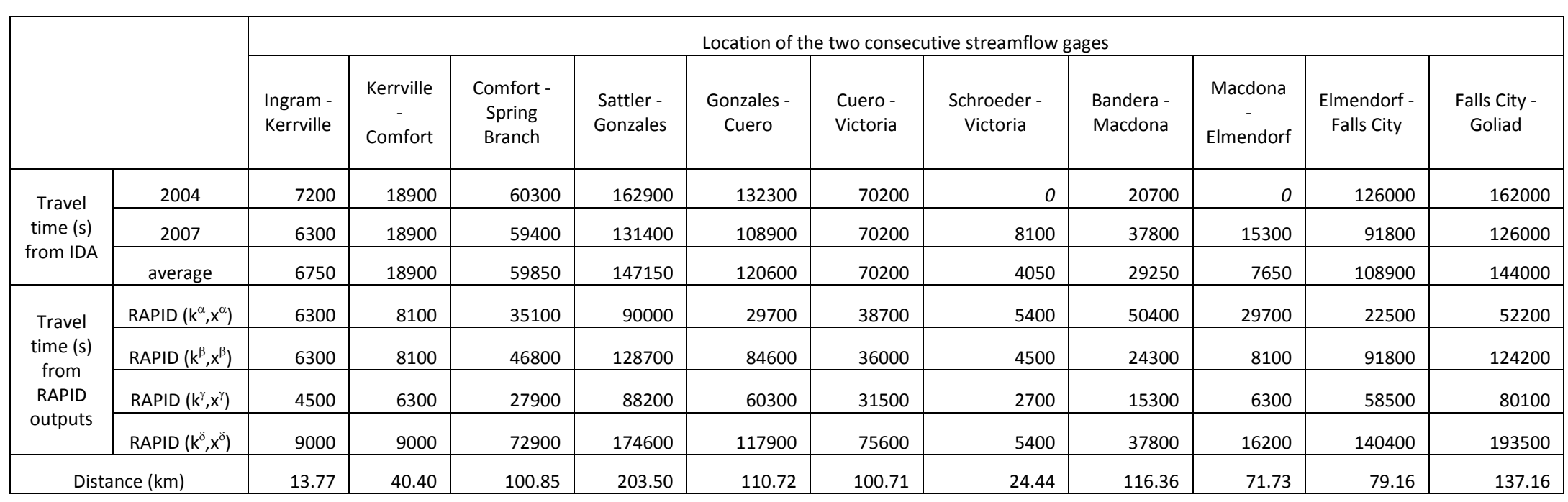


Table 2 Wave celerities $(\mathrm{m} / \mathrm{s})$ estimated using the lagged cross-correlation in the Guadalupe and San Antonio River Basins, both from IDA measurements and from RAPID model runs

\begin{tabular}{|c|c|c|c|c|c|c|c|c|c|c|c|c|}
\hline \multirow{2}{*}{\multicolumn{2}{|c|}{ Wave celerity $(\mathrm{m} / \mathrm{s})$}} & \multicolumn{11}{|c|}{ Location of the two consecutive streamflow gages } \\
\hline & & \multirow{2}{*}{$\begin{array}{r}\text { Ingram - } \\
\text { Kerrville } \\
1.91 \\
\end{array}$} & \multirow{2}{*}{$\begin{array}{r}\text { Kerrville } \\
\begin{array}{c}- \\
\text { Comfort }\end{array} \\
2.14 \\
\end{array}$} & \multirow{2}{*}{$\begin{array}{r}\begin{array}{c}\text { Comfort } \\
\text { - Spring } \\
\text { Branch }\end{array} \\
1.67\end{array}$} & \multirow{2}{*}{$\begin{array}{r}\text { Sattler - } \\
\text { Gonzales } \\
1.25 \\
\end{array}$} & \multirow{2}{*}{$\begin{array}{r}\begin{array}{c}\text { Gonzales } \\
\text { - Cuero }\end{array} \\
0.84\end{array}$} & \multirow{2}{*}{$\begin{array}{r}\begin{array}{r}\text { Cuero - } \\
\text { Victoria }\end{array} \\
1.43\end{array}$} & \multirow{2}{*}{$\begin{array}{r}\text { Schroeder } \\
\text { - Victoria } \\
\infty \\
\end{array}$} & \multirow{2}{*}{$\begin{array}{c}\begin{array}{c}\text { Bandera } \\
- \\
\text { Macdona }\end{array} \\
5.62\end{array}$} & \multirow{2}{*}{$\begin{array}{r}\begin{array}{c}\text { Macdona } \\
- \\
\text { Elmendorf }\end{array} \\
\infty\end{array}$} & \multirow{2}{*}{$\begin{array}{r}\text { Elmendorf } \\
\text { - Falls City } \\
0.63\end{array}$} & \multirow{2}{*}{$\begin{array}{r}\begin{array}{r}\text { Falls } \\
\text { City - } \\
\text { Goliad }\end{array} \\
0.85 \\
\end{array}$} \\
\hline \multirow{3}{*}{$\begin{array}{c}\text { from } \\
\text { IDA }\end{array}$} & 2004 & & & & & & & & & & & \\
\hline & 2007 & 2.19 & 2.14 & 1.70 & 1.55 & 1.02 & 1.43 & 3.02 & 3.08 & 4.69 & 0.86 & 1.09 \\
\hline & average & 2.05 & 2.14 & 1.69 & 1.40 & 0.93 & 1.43 & 3.02 & 4.35 & 4.69 & 0.75 & 0.97 \\
\hline \multirow{4}{*}{$\begin{array}{l}\text { from } \\
\text { RAPID } \\
\text { outputs }\end{array}$} & $\operatorname{RAPID}\left(k^{\alpha}, \mathbf{x}^{\alpha}\right)$ & 2.19 & 4.99 & 2.87 & 2.26 & 3.73 & 2.60 & 4.53 & 2.31 & 2.41 & 3.52 & 2.63 \\
\hline & $\operatorname{RAPID}\left(k^{\beta}, x^{\beta}\right)$ & 2.19 & 4.99 & 2.16 & 1.58 & 1.31 & 2.80 & 5.43 & 4.79 & 8.85 & 0.86 & 1.10 \\
\hline & $\operatorname{RAPID}\left(k^{\gamma}, \mathbf{x}^{\gamma}\right)$ & 3.06 & 6.41 & 3.61 & 2.31 & 1.84 & 3.20 & 9.05 & 7.61 & 11.38 & 1.35 & 1.71 \\
\hline & $\operatorname{RAPID}\left(k^{\delta}, x^{\delta}\right)$ & 1.53 & 4.49 & 1.38 & 1.17 & 0.94 & 1.33 & 4.53 & 3.08 & 4.43 & 0.56 & 0.71 \\
\hline
\end{tabular}


Table 3 Comparison of observed and simulated flows at fifteen locations within the Guadalupe and San Antonio River

Basins

\begin{tabular}{|c|c|c|c|c|c|c|c|c|c|c|c|c|c|c|c|c|c|}
\hline \multirow[b]{2}{*}{ Gaging station } & \multicolumn{6}{|c|}{ Average daily stream flow (m3/s) } & \multirow{2}{*}{$\begin{array}{l}\text { Flow ratio } \\
\text { Observed/Lumped } \\
\end{array}$} & \multicolumn{5}{|c|}{$\begin{array}{l}\text { RMS error (m3/s) using daily } \\
\text { averages }\end{array}$} & \multicolumn{5}{|c|}{ Nash efficiency using daily averages } \\
\hline & Observed L & Lumped & $\begin{array}{l}\text { RAPID } \\
\left(k^{\alpha}, x^{\alpha}\right)\end{array}$ & \begin{tabular}{|l|} 
RAPID \\
$\left(k^{\beta}, x^{\beta}\right)$ \\
\end{tabular} & $\begin{array}{l}\text { RAPID } \\
\left(k^{\gamma}, x^{\gamma}\right)\end{array}$ & $\mid \begin{array}{l}\text { RAPID } \\
\left(k^{\delta}, x^{\delta}\right)\end{array}$ & & Lumped & $\begin{array}{l}\text { RAPID } \\
\left(k^{\alpha}, x^{\alpha}\right) \\
\end{array}$ & $\begin{array}{l}\text { RAPID } \\
\left(k^{\beta}, x^{\beta}\right) \\
\end{array}$ & $\begin{array}{l}\text { RAPID } \\
\left(k^{\gamma}, x^{\gamma}\right)\end{array}$ & $\begin{array}{l}\text { RAPID } \\
\left(k^{\delta}, x^{\delta}\right)\end{array}$ & Lumped & \begin{tabular}{|l|} 
RAPID \\
$\left(k^{\alpha}, x^{\alpha}\right)$
\end{tabular} & $\begin{array}{l}\text { RAPID } \\
\left(k^{\beta}, x^{\beta}\right)\end{array}$ & $\begin{array}{l}\text { RAPID } \\
\left(k^{\gamma}, x^{\gamma}\right) \\
\end{array}$ & $\begin{array}{l}\text { RAPID } \\
\left(k^{\delta}, x^{\delta}\right)\end{array}$ \\
\hline Johnson Ck nr Ingram, TX & 1.16 & 0.06 & 0.06 & 0.06 & 0.06 & 0.06 & 19.33 & 4.41 & 4.41 & 4.41 & 4.41 & 4.41 & -0.05 & -0.05 & \begin{tabular}{|l|} 
\\
\end{tabular} & \begin{tabular}{|l|l|} 
& -0.05 \\
\end{tabular} & -0.05 \\
\hline Guadalupe Rv at Kerrville, TX & 4.15 & 0.14 & 0.14 & 0.14 & 0.14 & 0.14 & 29.64 & 15.04 & 15.04 & 15.04 & 15.04 & 15.04 & -0.06 & -0.05 & -0.05 & -0.05 & -0.06 \\
\hline Guadalupe Rv at Comfort, TX & 9.97 & 0.81 & 0.81 & 0.81 & 0.81 & 0.81 & 12.31 & 26.57 & 26.51 & 26.51 & 26.52 & 26.53 & -0.06 & -0.06 & -0.06 & \begin{tabular}{|l|l|} 
& -0.06 \\
\end{tabular} & -0.06 \\
\hline $\begin{array}{l}\text { Guadalupe Rv nr Spring Branch, } \\
\text { TX }\end{array}$ & 19.74 & 5.91 & 5.91 & 5.91 & 5.91 & 5.91 & 3.34 & 42.09 & 43.06 & 43.48 & 42.72 & 44.80 & 0.26 & 0.23 & 0.21 & 0.24 & 0.16 \\
\hline Guadalupe Rv at Sattler, TX & 22.04 & 6.62 & 6.62 & 6.62 & 6.62 & 6.62 & 3.33 & 40.08 & 39.85 & 39.77 & 39.94 & 39.57 & -0.06 & -0.04 & -0.04 & -0.05 & -0.03 \\
\hline Guadalupe Rv at Gonzales, TX & 64.28 & 23.27 & 23.27 & 23.27 & 23.27 & 23.27 & 2.76 & 79.83 & 80.93 & 86.44 & 80.40 & 93.78 & 0.45 & 0.44 & 0.36 & 0.45 & 0.25 \\
\hline Guadalupe Rv at Cuero, TX & 73.23 & 52.63 & 52.62 & 52.61 & 52.62 & 52.60 & 1.39 & 76.86 & 56.41 & 64.91 & 55.52 & 82.74 & 0.59 & 0.78 & 0.71 & 0.79 & 0.53 \\
\hline Guadalupe Rv nr Victoria & 80.96 & 61.95 & 61.93 & 61.92 & 61.93 & 61.91 & 1.31 & 93.97 & 70.11 & 65.07 & 68.05 & 89.06 & 0.54 & 0.75 & 0.78 & 0.76 & 0.59 \\
\hline $\begin{array}{l}\text { Coleto Ck at Arnold Rd nr } \\
\text { Schroeder, TX } \\
\end{array}$ & 3.45 & 8.78 & 8.78 & 8.78 & 8.78 & 8.78 & 0.39 & 15.43 & 15.44 & 15.45 & 15.46 & 15.44 & 0.03 & 0.03 & 0.03 & 0.02 & 0.03 \\
\hline Coleto Ck nr Victoria, TX & 3.99 & 13.72 & 13.72 & 13.72 & 13.72 & 13.72 & 0.29 & 21.82 & 22.61 & 22.46 & 22.26 & 22.65 & 0.10 & 0.03 & 0.05 & 0.06 & 0.03 \\
\hline Medina Rv at Banderas, TX & 5.30 & 0.75 & 0.75 & 0.75 & 0.75 & 0.75 & 7.07 & 10.78 & 10.77 & 10.77 & 10.77 & 10.77 & 0.05 & 0.05 & 0.05 & 0.05 & 0.05 \\
\hline Medina Rv nr Macdona, TX & 8.73 & 2.09 & 2.09 & 2.09 & 2.09 & 2.09 & 4.18 & 12.89 & 12.74 & 12.72 & 12.74 & 12.72 & 0.29 & 0.31 & 0.31 & 0.30 & 0.31 \\
\hline $\begin{array}{l}\text { San Antonio Rv nr Elmendorf, } \\
\text { TX }\end{array}$ & 25.05 & 7.95 & 7.95 & 7.95 & 7.95 & 7.95 & 3.15 & 39.91 & 39.27 & 39.23 & 39.41 & 39.16 & 0.34 & 0.36 & 0.36 & 0.36 & 0.37 \\
\hline San Antonio Rv nr Falls City, TX & 25.01 & 12.36 & 12.36 & 12.36 & 12.36 & 12.36 & 2.02 & 33.23 & 31.13 & 30.63 & 31.26 & 32.00 & 0.45 & 0.52 & 0.53 & 0.51 & 0.49 \\
\hline San Antonio Rv at Goliad, TX & 37.54 & 34.96 & 34.95 & 34.95 & 34.95 & 34.94 & 1.07 & 42.34 & 37.73 & 34.58 & 36.92 & 39.10 & 0.56 & 0.65 & 0.71 & 0.67 & 0.63 \\
\hline Mean & 25.64 & 15.47 & 15.46 & 15.46 & 15.46 & 15.46 & & 37.02 & 33.73 & 34.10 & 33.43 & 37.85 & 0.23 & 0.26 & 0.26 & 0.27 & 0.22 \\
\hline
\end{tabular}


Table 4 Results of the Wilcoxon signed-ranks test applied to fifteen stations for efficiency and RMSE and to various routing procedures

\begin{tabular}{|c|c|c|c|c|c|c|c|}
\hline \multicolumn{8}{|l|}{ Efficiency } \\
\hline$x$ & $y$ & $\begin{array}{l}\text { Number of non- } \\
\text { zero differences }\end{array}$ & Total rank & $\begin{array}{l}W^{+} \text {(computed } \\
\text { for } y-x)\end{array}$ & $\begin{array}{l}p \text {-value } \\
\text { corresponding to } \\
\mathrm{W}^{+}\end{array}$ & $\begin{array}{l}\text { W' (computed } \\
\text { for } y-x)\end{array}$ & \begin{tabular}{|l}
$p$-value \\
corresponding to \\
$W^{-}$
\end{tabular} \\
\hline Lumped runoff & $\operatorname{RAPID}\left(k^{\alpha}, x^{\alpha}\right)$ & 11 & 66 & 51.0 & 0.06152 & 15.0 & 0.94922 \\
\hline Lumped runoff & RAPID $\left(k^{\beta}, x^{\beta}\right)$ & 11 & 66 & 47.0 & 0.12012 & 19.0 & 0.89697 \\
\hline Lumped runoff & RAPID $\left(k^{\gamma}, x^{\gamma}\right)$ & 11 & 66 & 51.0 & 0.06152 & 15.0 & 0.94922 \\
\hline Lumped runoff & RAPID $\left(k^{\delta}, x^{\delta}\right)$ & 10 & 55 & 22.5 & 0.70459 & 32.5 & 0.33008 \\
\hline RAPID $\left(k^{\alpha}, x^{\alpha}\right)$ & $\operatorname{RAPID}\left(\mathbf{k}^{\gamma}, \mathbf{x}^{\gamma}\right)$ & 10 & 55 & 37.0 & 0.18750 & 18.0 & 0.83887 \\
\hline RAPID $\left(k^{\beta}, x^{\beta}\right)$ & RAPID $\left(k^{\gamma}, x^{\gamma}\right)$ & 10 & 55 & 28.5 & 0.48047 & 26.5 & 0.55811 \\
\hline RAPID $\left(k^{\gamma}, x^{\gamma}\right)$ & RAPID $\left(k^{\delta}, x^{\delta}\right)$ & 12 & 78 & 13.0 & 0.98291 & 65.0 & 0.02124 \\
\hline
\end{tabular}

\begin{tabular}{|c|c|c|c|c|c|c|c|}
\hline \multicolumn{8}{|l|}{ RMSE } \\
\hline$x$ & y & $\begin{array}{l}\text { Number of non- } \\
\text { zero differences }\end{array}$ & Total rank & $\begin{array}{l}W^{+} \text {(computed } \\
\text { for } y-x)\end{array}$ & $\begin{array}{l}\mathrm{p} \text {-value } \\
\text { corresponding to } \\
\mathrm{W}^{+}\end{array}$ & $\begin{array}{l}\text { W- (computed } \\
\text { for } y-x)\end{array}$ & \begin{tabular}{|l} 
p-value \\
corresponding to \\
$W^{-}$
\end{tabular} \\
\hline Lumped runoff & $\operatorname{RAPID}\left(k^{\alpha}, x^{\alpha}\right)$ & 13 & 91 & 25.5 & 0.92145 & 65.5 & 0.08966 \\
\hline Lumped runoff & $\operatorname{RAPID}\left(k^{\beta}, x^{\beta}\right)$ & 13 & 91 & 26.0 & 0.91614 & 65.0 & 0.09546 \\
\hline Lumped runoff & $\operatorname{RAPID}\left(\mathrm{k}^{\gamma}, \mathbf{x}^{\gamma}\right)$ & 13 & 91 & 25.0 & 0.92676 & 66.0 & 0.08386 \\
\hline Lumped runoff & RAPID $\left(k^{\delta}, x^{\delta}\right)$ & 13 & 91 & 42.5 & 0.59345 & 48.5 & 0.43299 \\
\hline $\operatorname{RAPID}\left(k^{\alpha}, x^{\alpha}\right)$ & $\operatorname{RAPID}\left(\mathrm{k}^{\gamma}, \mathbf{x}^{\gamma}\right)$ & 11 & 66 & 15.0 & 0.94922 & 51.0 & 0.06152 \\
\hline RAPID $\left(k^{\beta}, x^{\beta}\right)$ & RAPID $\left(k^{\gamma}, x^{\gamma}\right)$ & 12 & 78 & 41.0 & 0.45483 & 37.0 & 0.57495 \\
\hline RAPID $\left(k^{\gamma}, x^{\gamma}\right)$ & RAPID $\left(k^{\delta}, x^{\delta}\right)$ & 12 & 78 & 64.0 & 0.02612 & 14.0 & 0.97876 \\
\hline
\end{tabular}




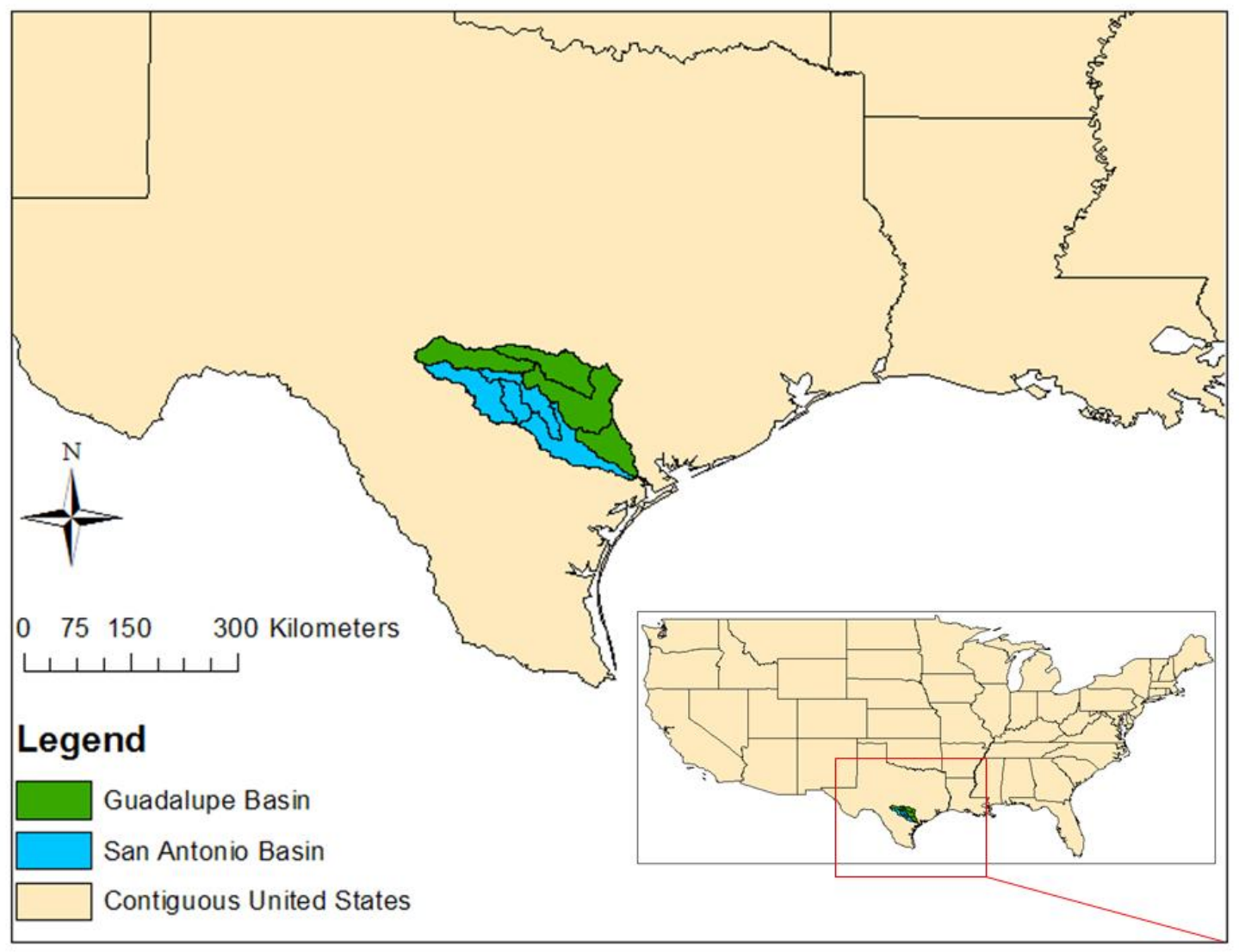

Figure 1 Guadalupe and San Antonio Basins 


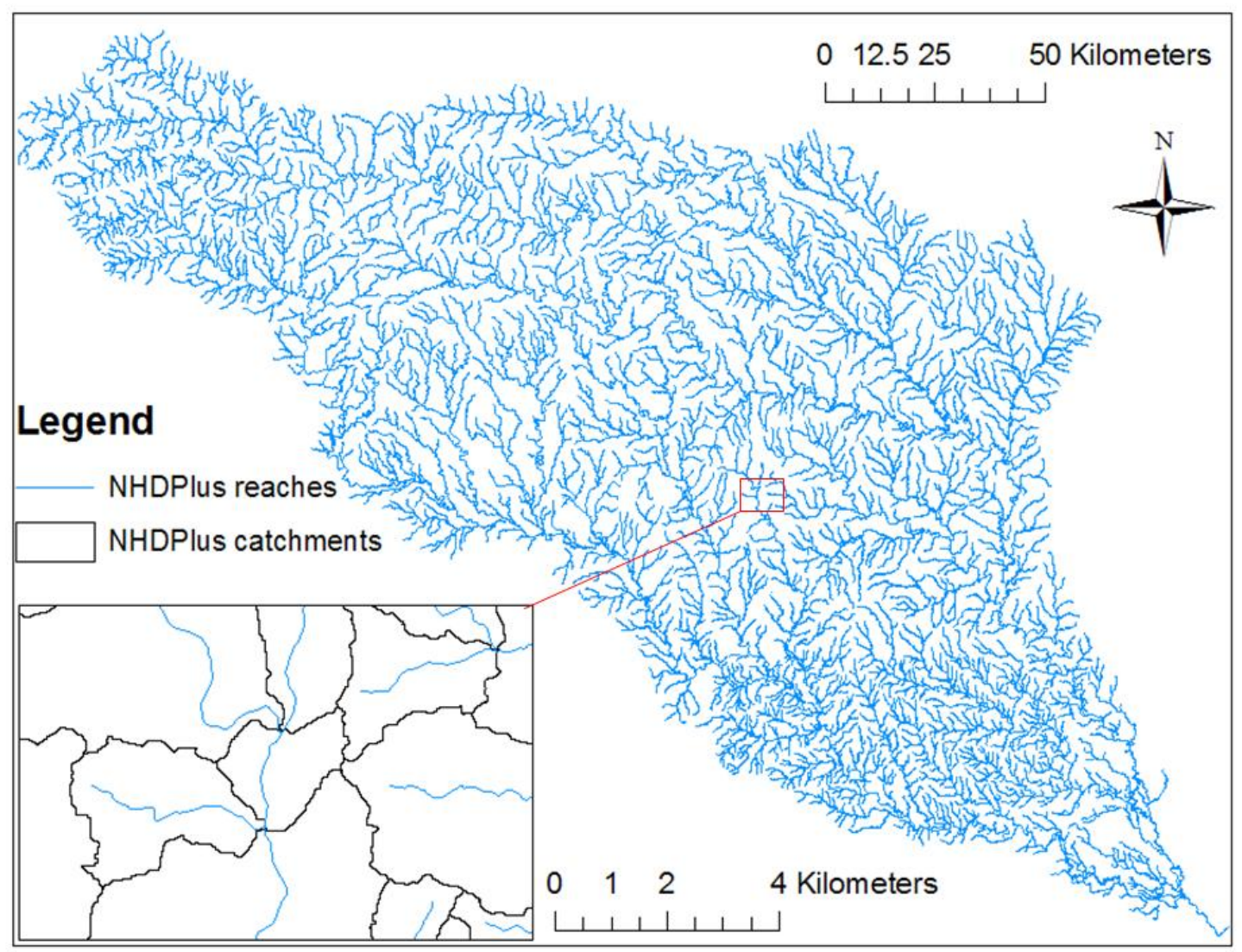

Figure 2 NHDPlus river network and catchments for the Guadalupe and San Antonio Basins 


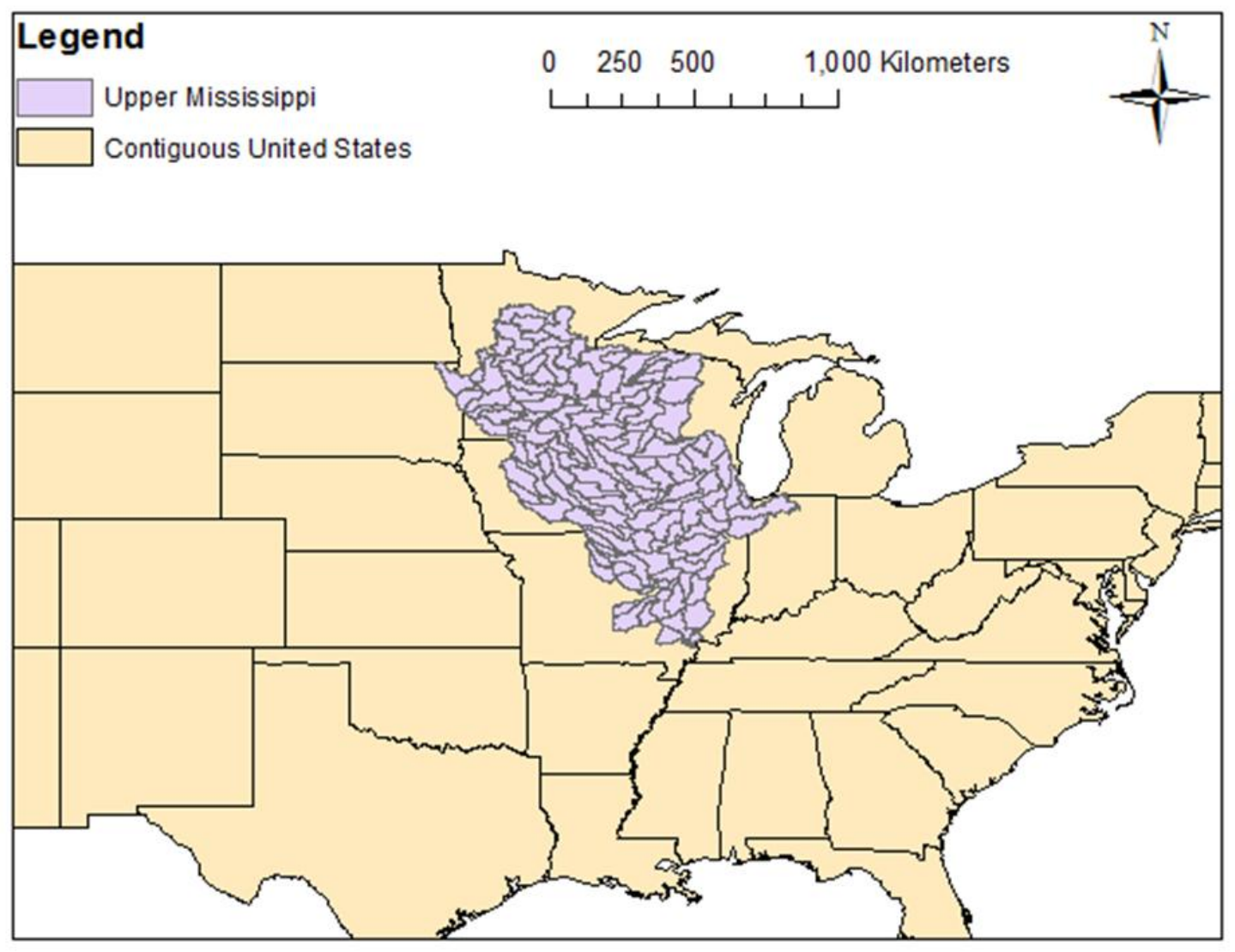

Figure 3 Upper Mississippi River Basin 


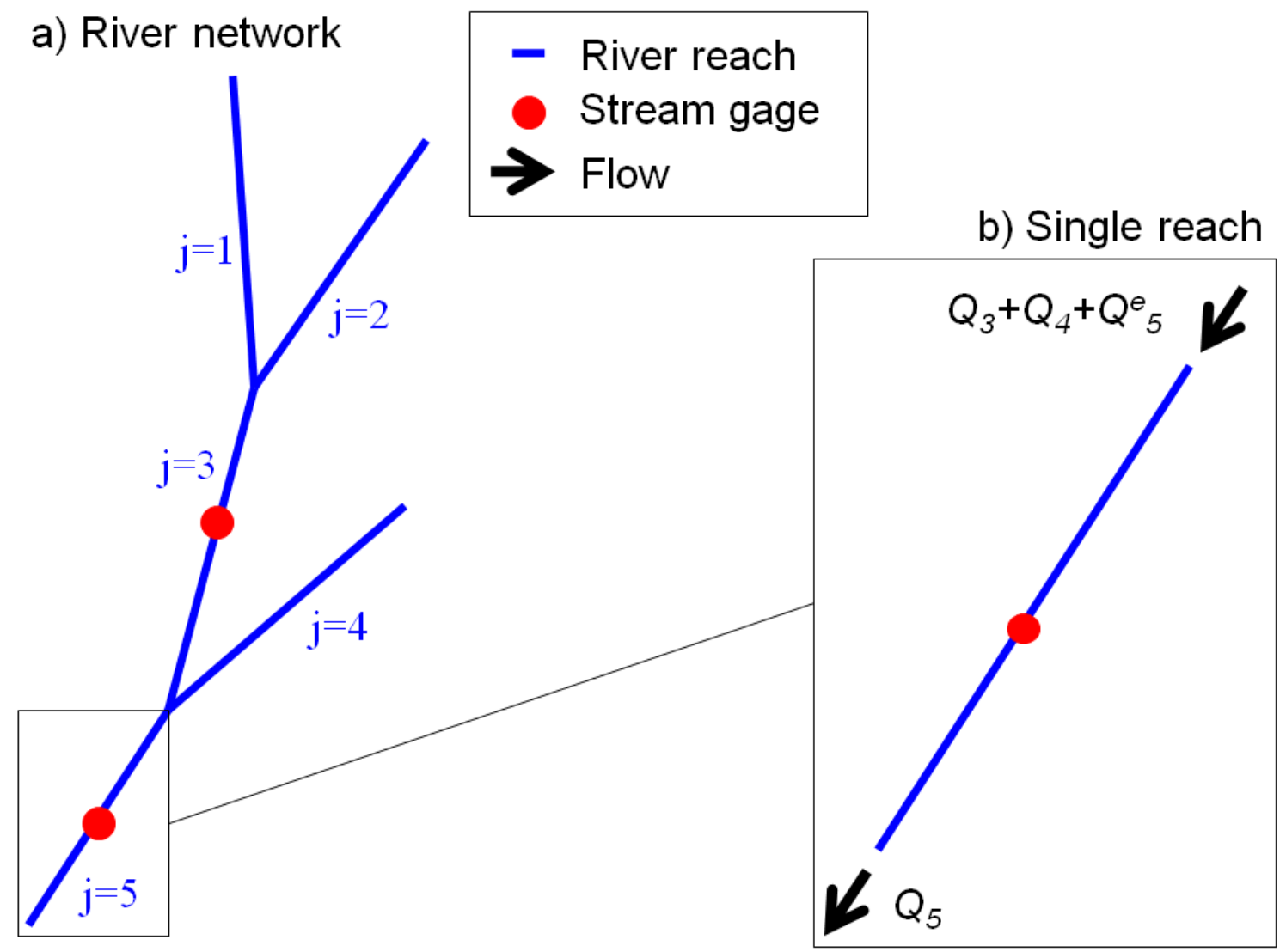

Figure 4 River network 

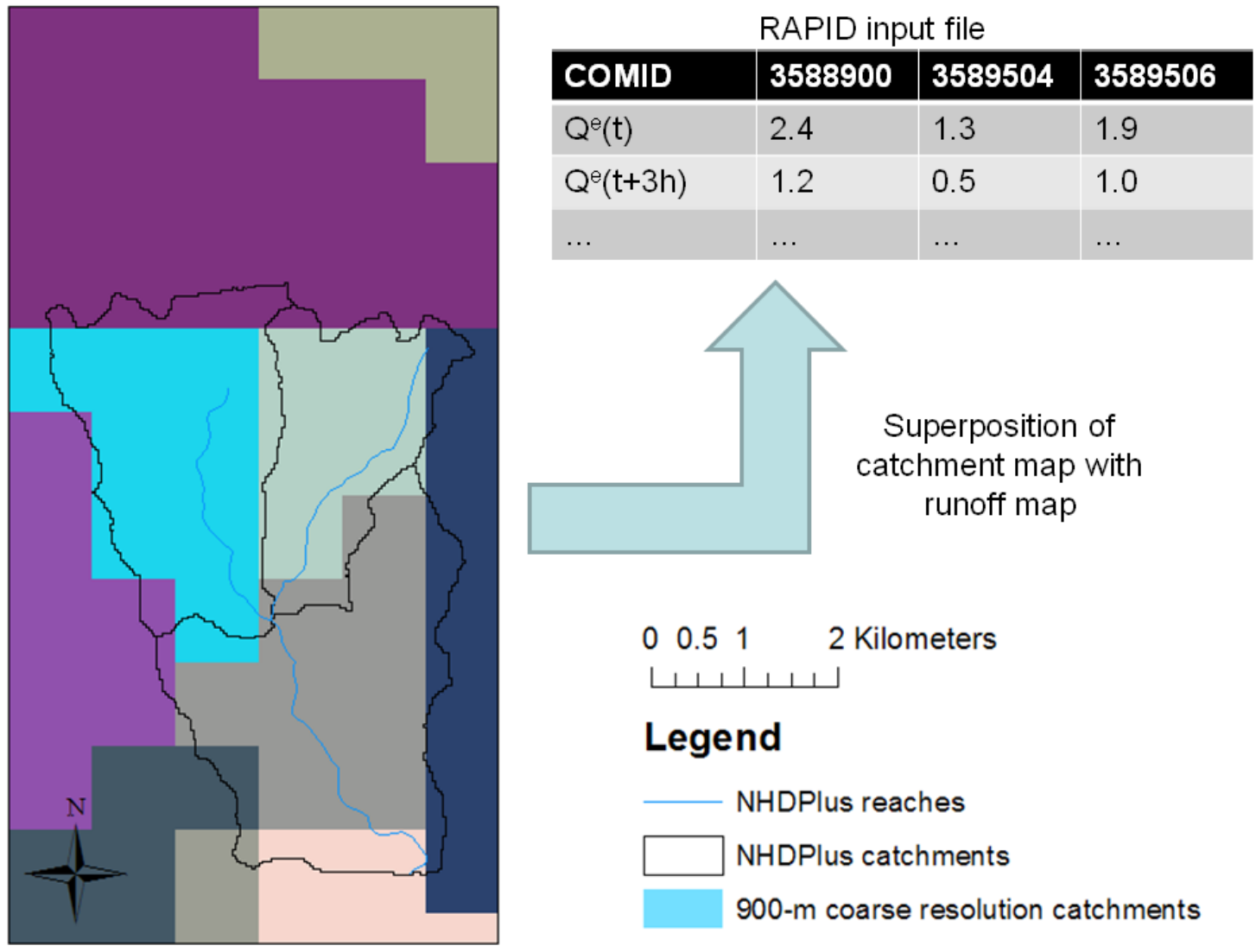

Figure 5 Principle of flux coupler between Noah and RAPID 


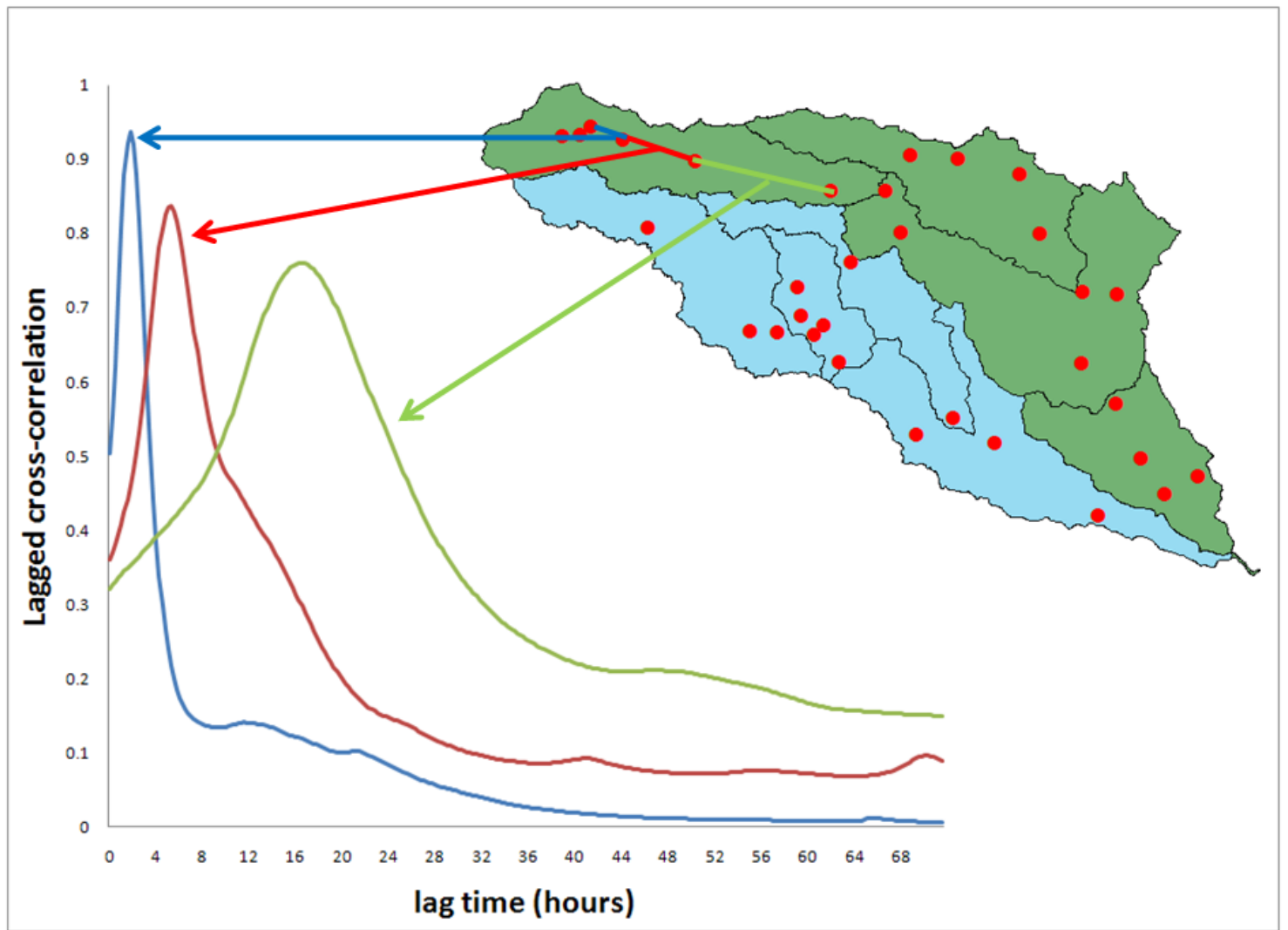

Figure 6 Lagged cross-correlation as a function of lag time 


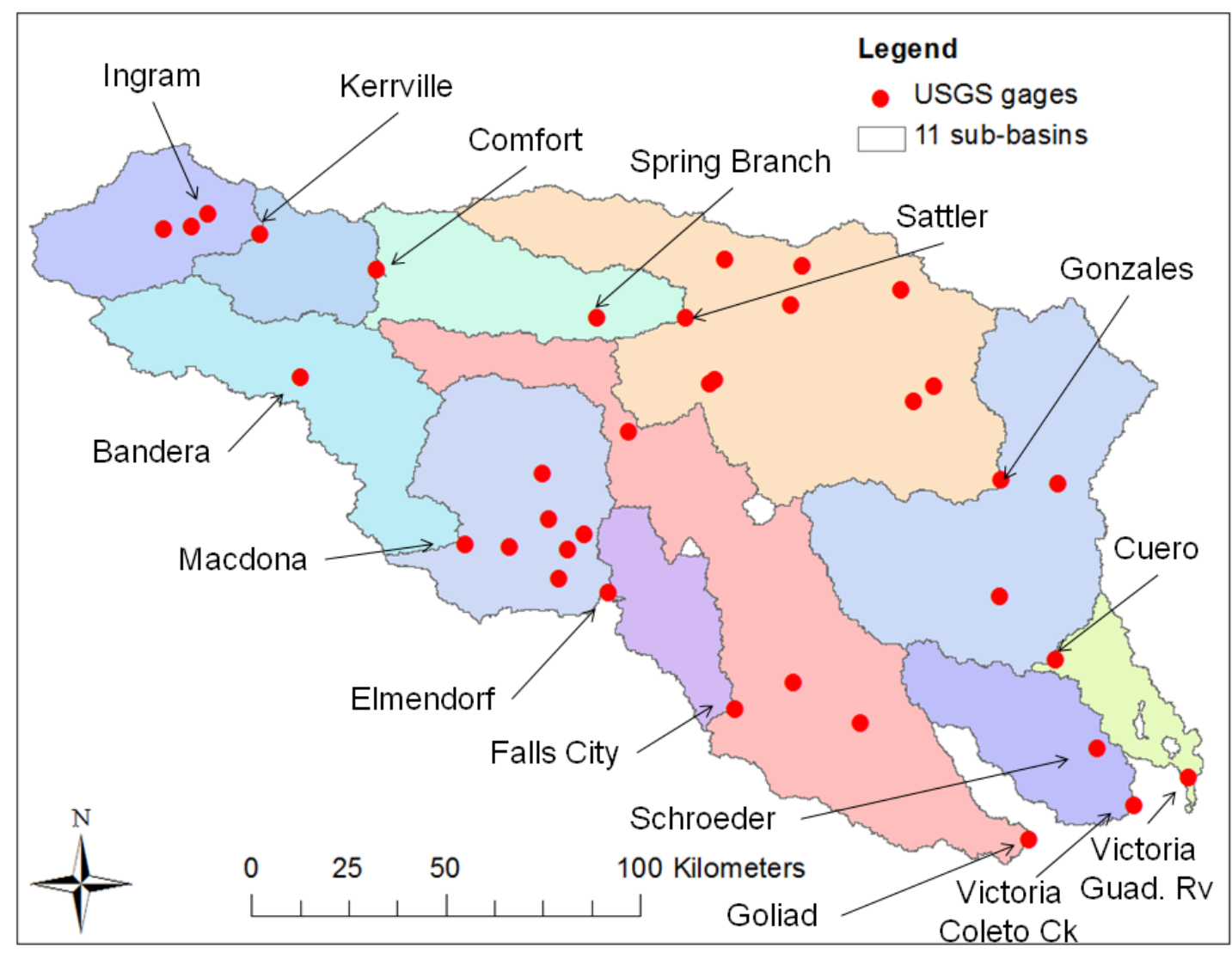

Figure 7 Wave celerities are estimated for eleven different sub-basins within the Guadalupe and San Antonio river basins. Location of 36 gaging stations used for optimization and names of the 15 gaging stations used for estimation of wave celerities. The same sub-basins are used for distributed parameters in RAPID 


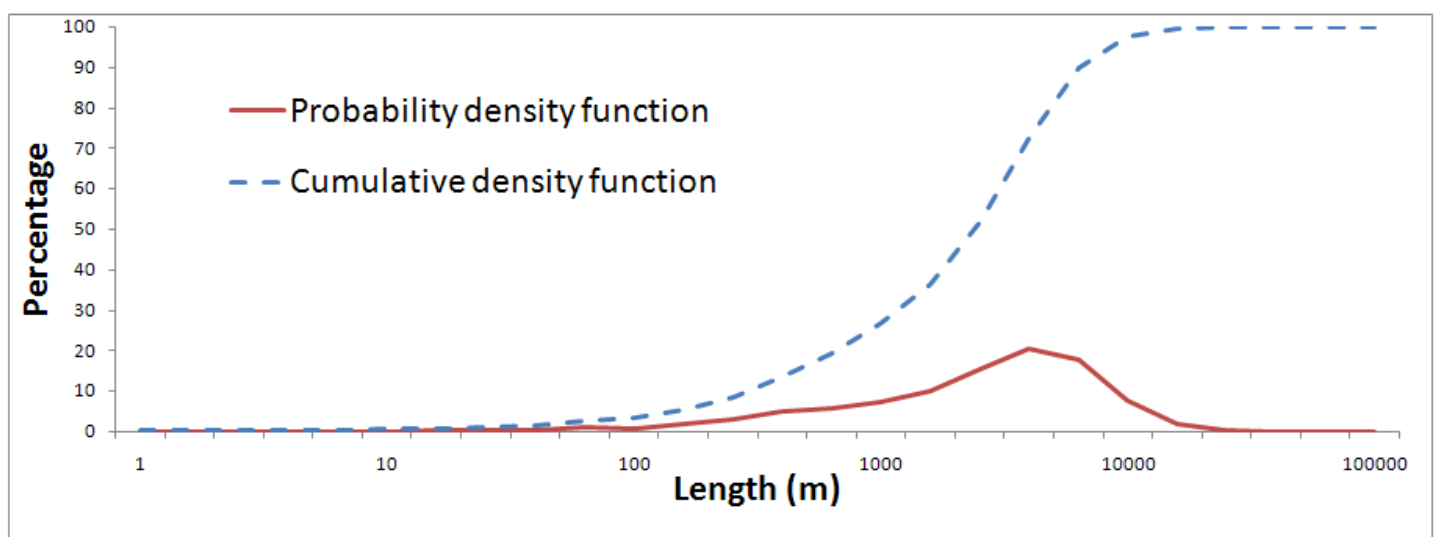

Figure 8 Statistics of river reach lengths in Guadalupe and San Antonio River Basins 


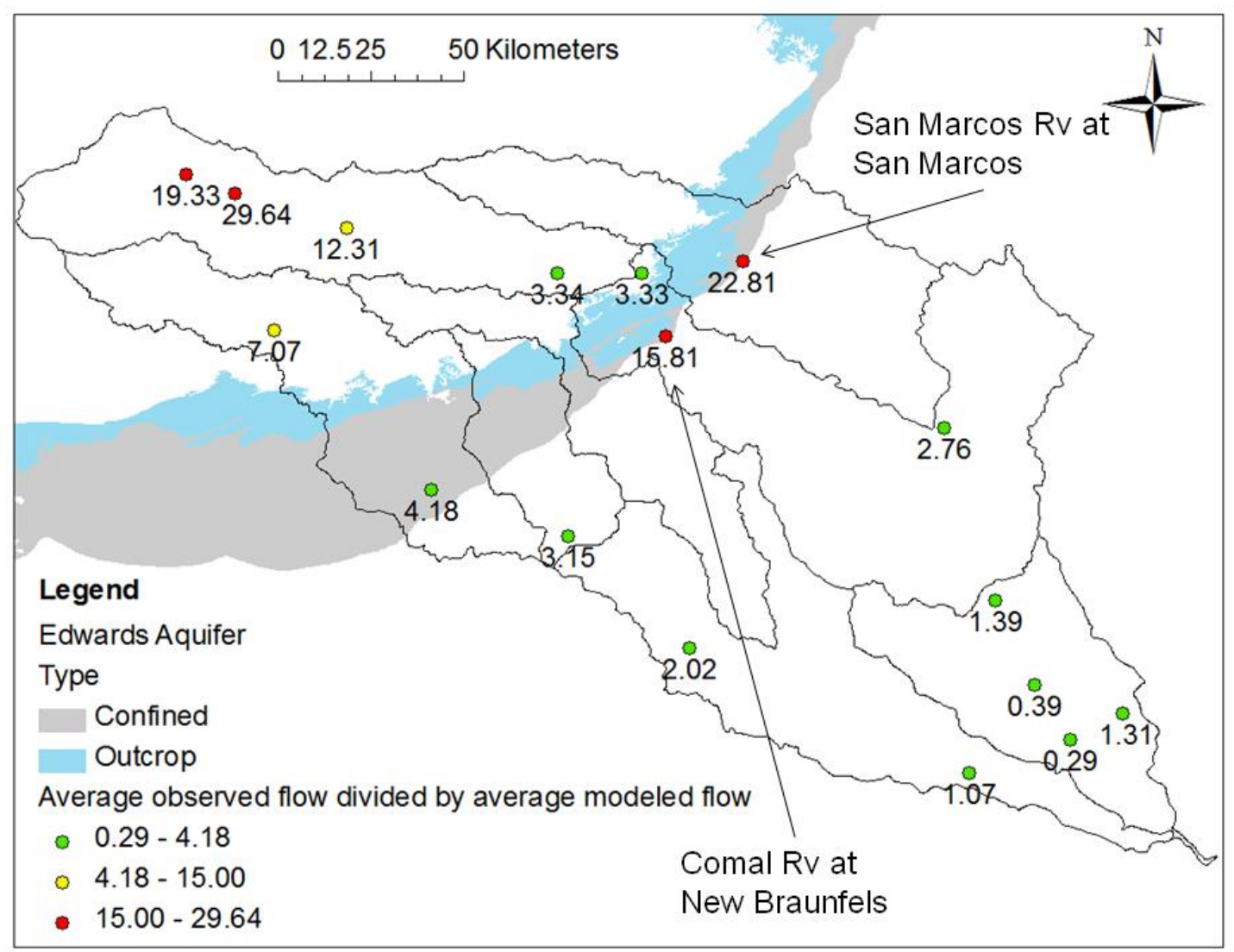

Figure 9 Ratio between observed and modeled stream flow at 16 gages, location of the Edwards Aquifer. Location of the two largest springs in Texas. 


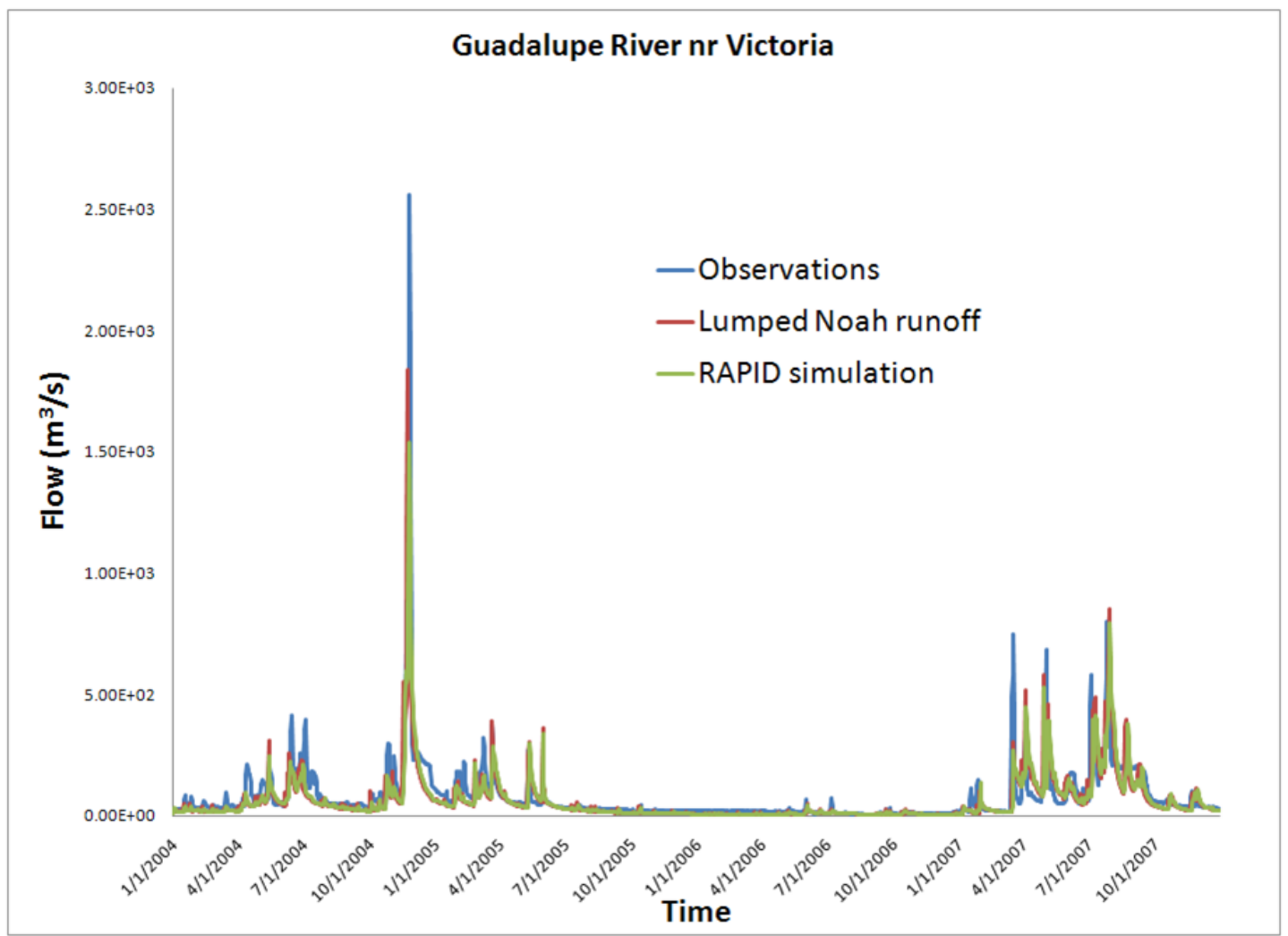

Figure 10 Hydrograph of observed, lumped and routed flows for the Guadalupe River near Victoria, using $\left(\mathrm{k}^{\gamma}, \mathrm{x}^{\gamma}\right)$ 


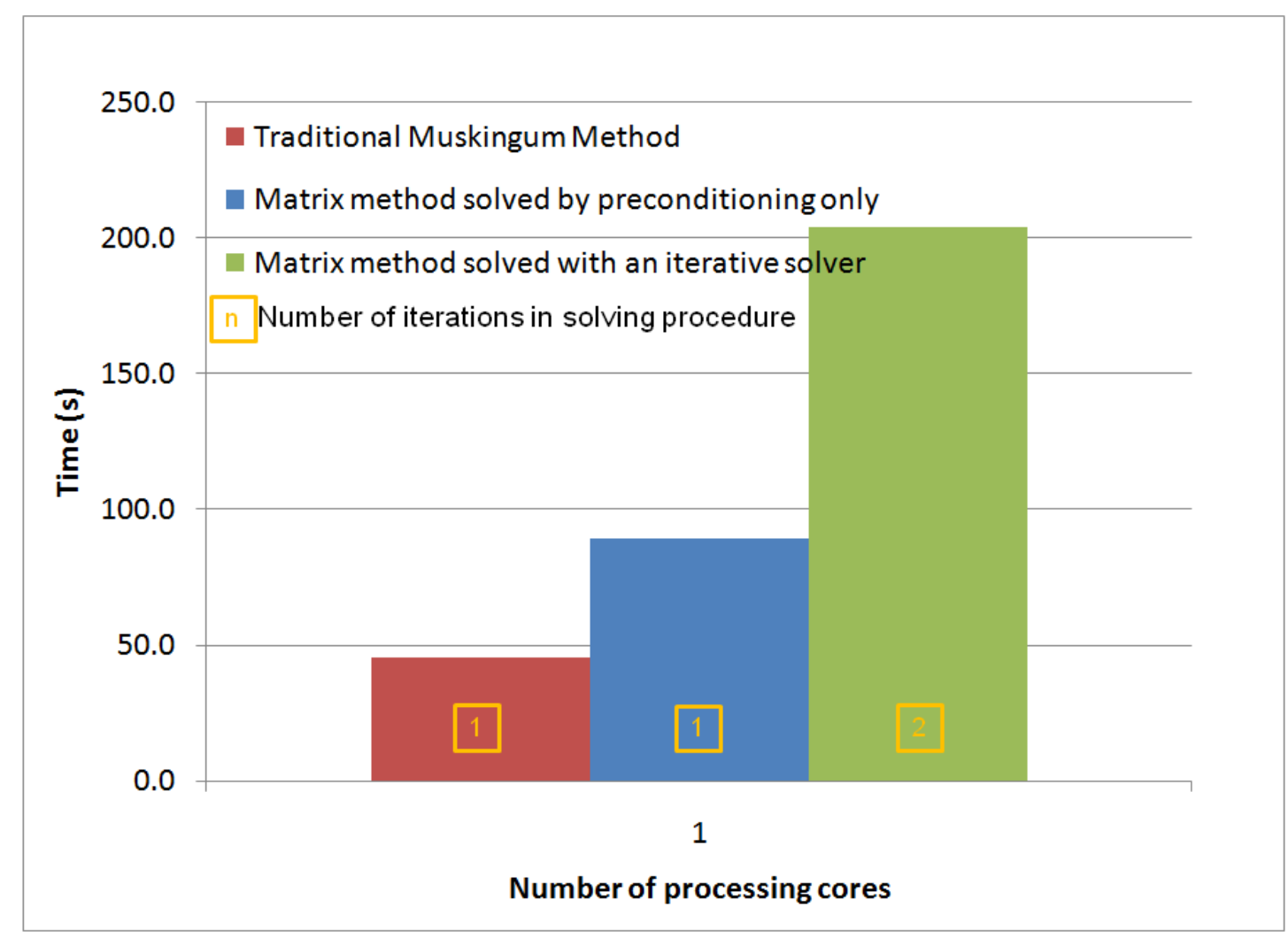

Figure 11 Comparison of computing time between the traditional Muskingum method and matrix methods 


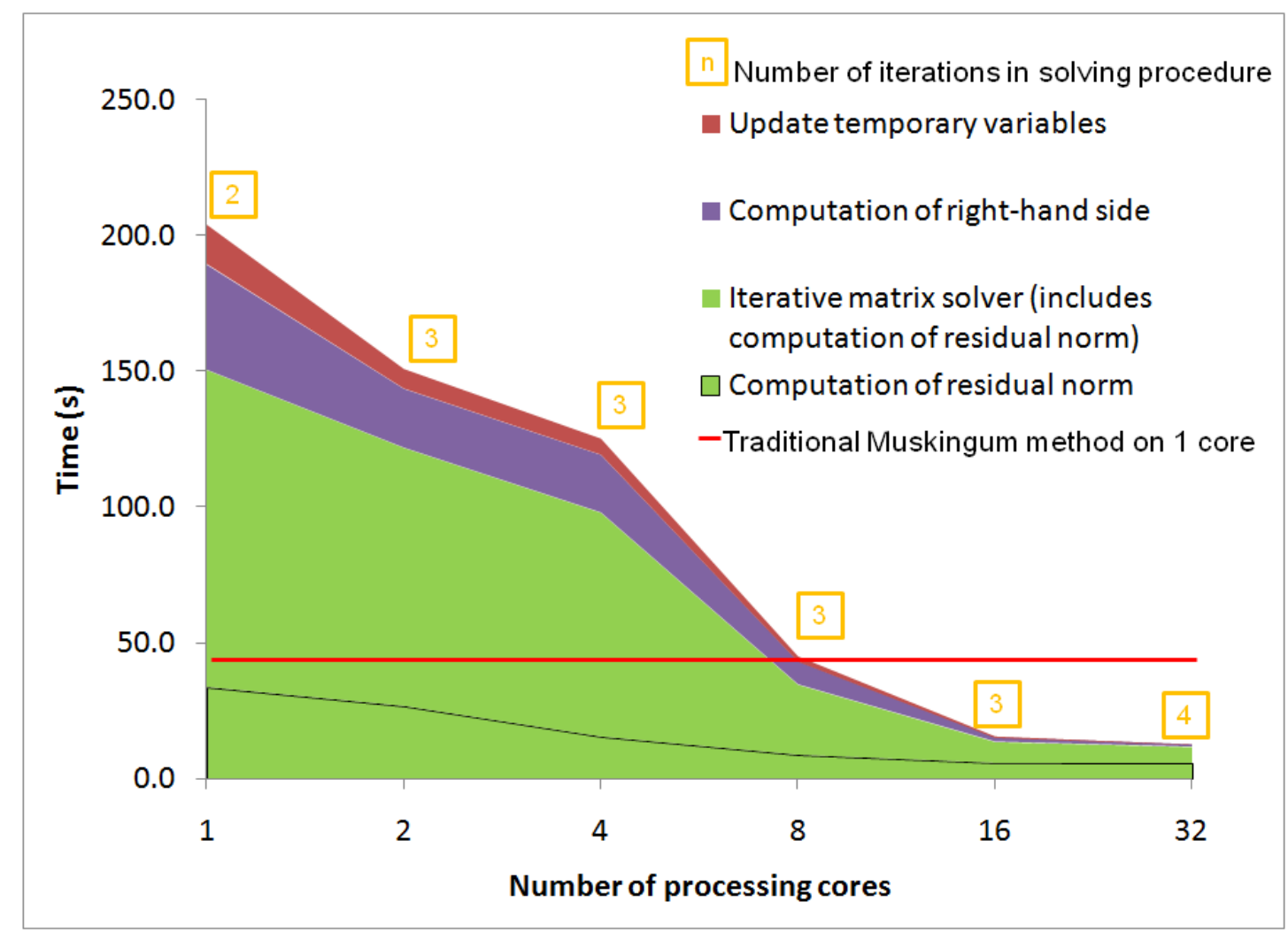

Figure 12 Total computing time for matrix method with an iterative solver as a function of the number of processing cores, number of iterations needed, total computing time for the traditional Muskingum method. 

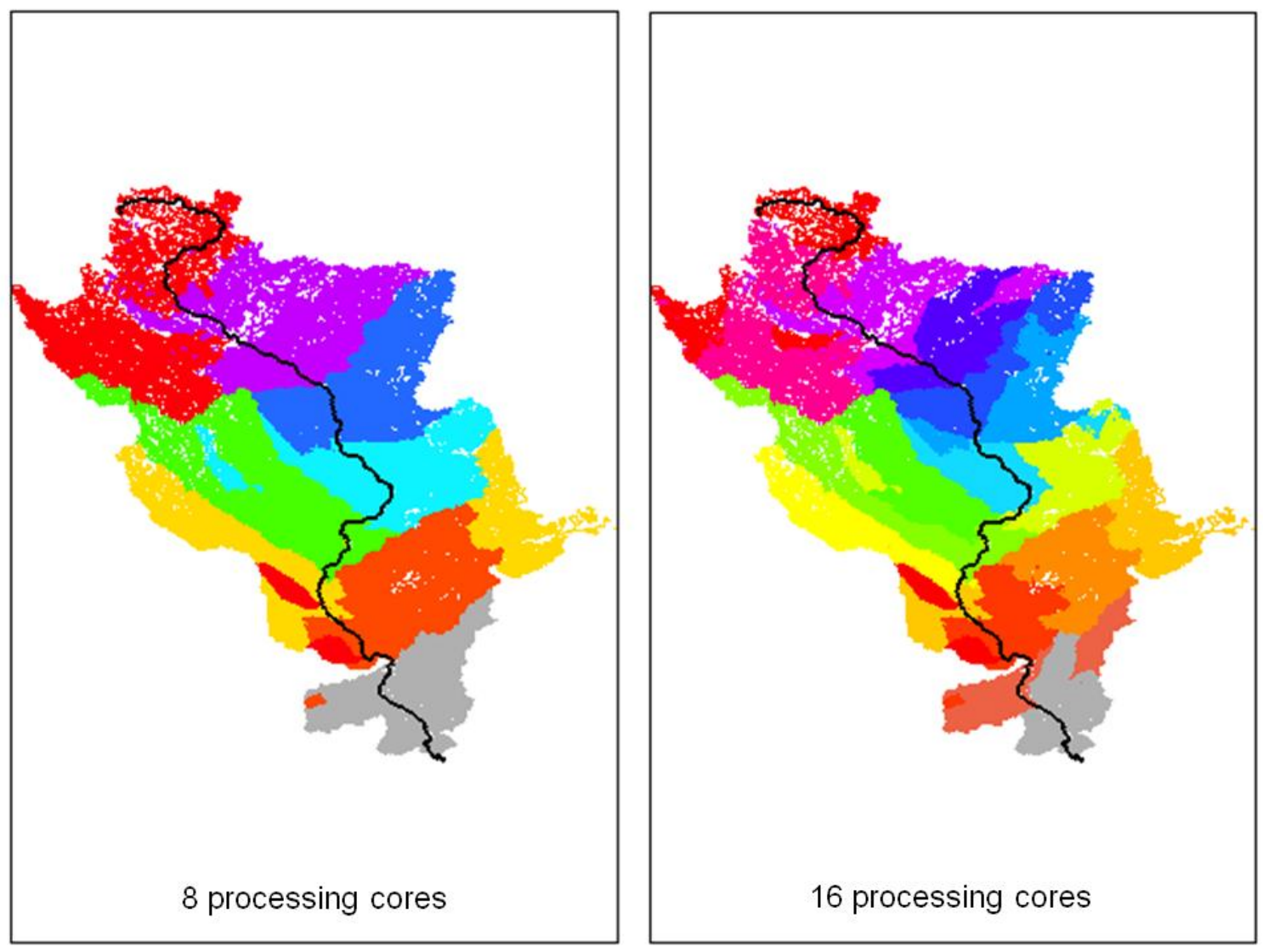

Figure 13 Longest path in the Upper Mississippi River Basin and location of sub-basins when RAPID is used in a parallel computing environment with 8 and 16 processing cores, different colors correspond to different cores. 


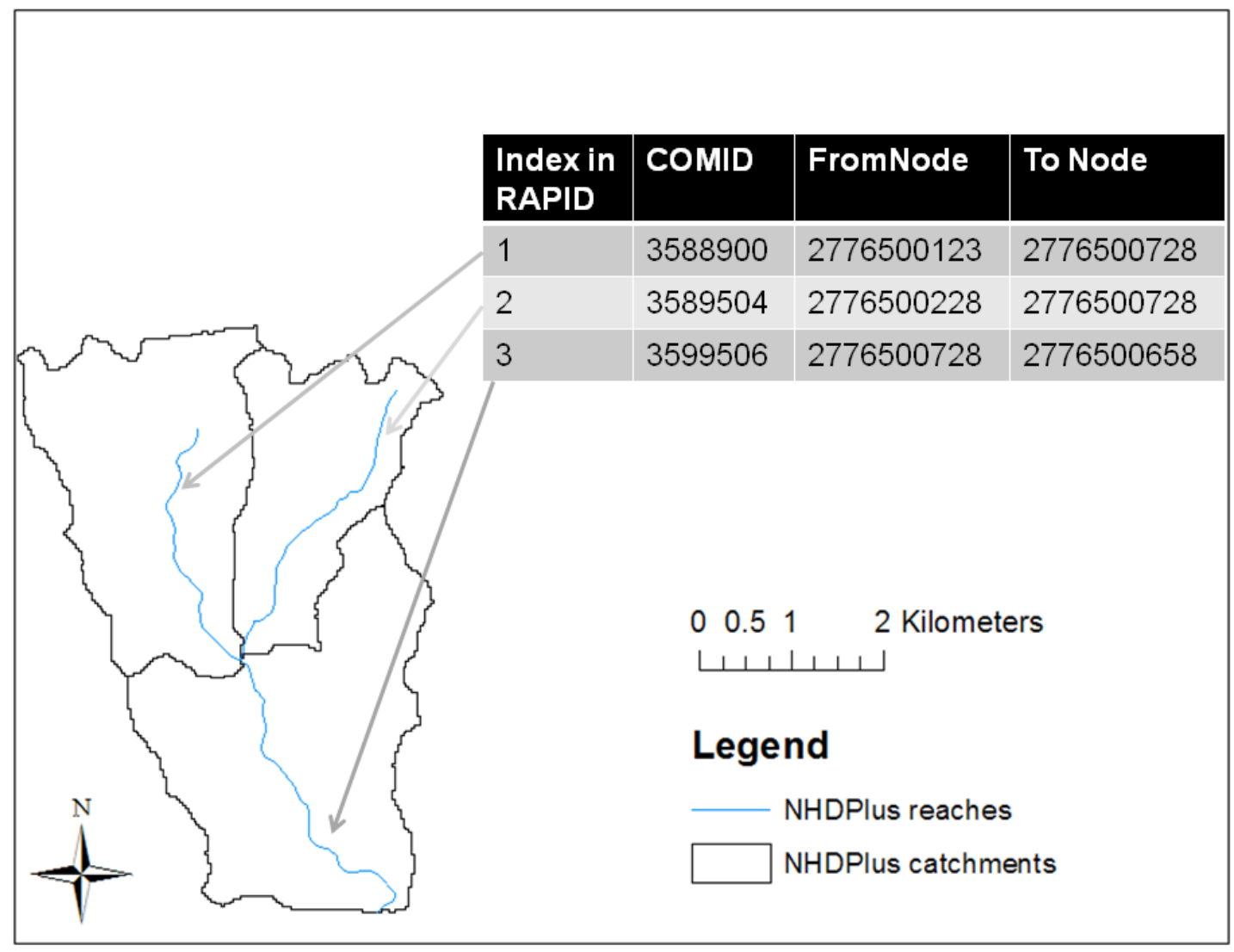

Figure 14 NHDPlus connectivity between reaches, nodes and catchments 


\section{Figure captions}

Figure 1 Guadalupe and San Antonio Basins

Figure 2 NHDPlus river network and catchments for the Guadalupe and San Antonio Basins

Figure 3 Upper Mississippi River Basin

Figure 4 River network

Figure 5 Principle of flux coupler between Noah and RAPID

Figure 6 Lagged cross-correlation as a function of lag time

Figure 7 Wave celerities are estimated for eleven different sub-basins within the Guadalupe and San Antonio river basins. Location of 36 gaging stations used for optimization and names of the 15 gaging stations used for estimation of wave celerities. The same sub-basins are used for distributed parameters in RAPID

Figure 8 Statistics of river reach lengths in Guadalupe and San Antonio River Basins

Figure 9 Ratio between observed and modeled stream flow at 16 gages, location of the Edwards Aquifer. Location of the two largest springs in Texas.

Figure 10 Hydrograph of observed, lumped and routed flows for the Guadalupe River near Victoria, using $\left(\mathrm{k}^{\gamma}, \mathrm{x}^{\gamma}\right)$

Figure 11 Comparison of computing time between the traditional Muskingum method and matrix methods

Figure 12 Total computing time for matrix method with an iterative solver as a function of the number of processing cores, number of iterations needed, total computing time for the traditional Muskingum method. 
Figure 13 Longest path in the Upper Mississippi River Basin and location of sub-basins when RAPID is used in a parallel computing environment with 8 and 16 processing cores, different colors correspond to different cores.

Figure 14 NHDPlus connectivity between reaches, nodes and catchments 